\title{
Remote Power Control Injection of Grid-Connected Power Converters Based on Virtual Flux
}

\author{
Nurul Fazlin Roslan ${ }^{1,2, *}$, Alvaro Luna ${ }^{1}$, Joan Rocabert ${ }^{1}$, Jose Ignacio Candela ${ }^{1}$ (i) and \\ Pedro Rodriguez ${ }^{1,3}$ \\ 1 Electrical Engineering Department, Technical University of Catalonia, 08222 Barcelona, Spain; \\ luna@ee.upc.edu (A.L.); rocabert@ee.upc.edu (J.R.); candela@ee.upc.edu (J.I.C.); \\ prodriguez@uloyola.es (P.R.) \\ 2 Electrical Technology Section, Universiti Kuala Lumpur, British Malaysian Institute, \\ Gombak 53100, Malaysia \\ 3 Department of Engineering, Loyola University of Andalucia, 41014 Seville, Spain \\ * Correspondence: nurulfazlin@unikl.edu.my; Tel.: +34-603247863
}

Received: 15 January 2018; Accepted: 19 February 2018; Published: 26 February 2018

\begin{abstract}
Renewable Energy Source (RES)-based power plants need to control the active and reactive power at the Point of Common Connection (PCC) with the grid, in order to comply with the requirements of the Transmission System Operators (TSOs). This point is normally far away from the power converter station, and the cables and step-up transformers have a non-neglectable influence on the delivered power. In order to overcome this drawback, this paper presents a control algorithm that permits one to control remotely the power injected at the PCC, by adjusting the local controller of the Voltage Source Converters (VSCs). In this work, the synchronization with the grid is done based on the Virtual Flux (VF) concept. The results reveals that the VF estimation is able to produce a reliable estimation of the grid voltage in any point of the network, and makes it possible to calculate the necessary current reference for injecting a desired active and reactive power at a point that can be some kilometres away. In this paper the main principle for this remote power control is presented. Likewise, the simulation and experimental results will be shown in order to analyse the effectiveness of the proposed system.
\end{abstract}

Keywords: voltage sensorless; virtual flux estimation; voltage source converter; proportional resonant current controller; LCL-filter; remote point

\section{Introduction}

The prospects of renewable energy integration during the next years is still very optimistic. In fact, Renewable energy sources (RESs) have become one of the most cost-competitive options for energy generation, being solar photovoltaic, wind energy and hydropower the ones leading the ranking of renewable energy capacity installation in 2015 according to the International Renewable Energy Agency Report 2017 ([1], p. 18). In these generation systems, the use of power converters and its controllability are key elements for achieving an effective grid integration of PV and wind power plants. The control strategy of these grid-connected power converters, especially the current control layer, can be performed in an $\alpha \beta$ stationary reference frame, a $d q 0$ synchronous reference frame, or in an $a b c$ reference frame. For each of these reference frames, various control strategies have been developed, tested and extensively discussed in the literature [2-4].

No matter the approach, grid synchronization is normally required for performing an instantaneous monitoring of the state of the grid, as well as to estimate the frequency, phase and magnitude of the voltage. The synchronization of power converters with the grid can be performed either by direct measurement of the grid voltage [5] or by adopting a voltage sensorless [6] control 
solution. Voltage sensorless control has become an attractive solution because it can reduce costs by means of reducing the number of sensors needed, which also contributes to increase the system modularity. In the implementation of voltage sensorless control, the Direct Power Control (DPC) and the Voltage Oriented Control (VOC) strategies are commonly used. Likewise, Virtual Flux (VF) estimation [7] is one of the simplest way to achieve voltage sensorless control by estimating the grid voltage condition. In $[8,9]$, a comparison of the voltage-based control and the VF-based control both working in DPC and VOC were presented. A few examples of the virtual flux working only in DPC mode have been presented in the literature [10-13] while the work presented in [14] is an example of the work related to virtual flux implementation in the VOC strategy.

In [15], a dual virtual flux model was implemented based on two cascaded low pass filters. In this work, the control implementation was performed in the stationary reference frame. As the cascaded structure presented in [15] could lead to a slower transient response, the works in [16-18] proposed to simplify this structure and improve the dynamic performance by means of using the advantages of the Dual Second Order Generalized Integrator Frequency Locked Loop (DSOGI-FLL). However, these works were only focused on grid-connected power converters with LC and L filters, while the vast majority of converters in RES applications use an LCL filter. Only a few studies have previously considered VF-based voltage sensorless grid synchronization with LCL-filters [19-21]. In this regard, the work presented in [22] is the extended version of the work done in [16] where the VF estimation has been carried out considering that the inverter is connected to the grid through the LCL filter. However, the work performed in [22] constitutes just an initial analysis and it is only validated through simulation results.

This paper goes further in the analysis of grid connected power converters with LCL filter connections and presents a control method based on the VF approach, which is able to control the power injection not only at the second inductor of the filter, but also in a remote point of the line where it is connected. The goal of this work is to control the active and reactive power injection at the point of connection by adopting the VF-based synchronization method, extending thus the work done in [16,19-22]. In this case, the control system will be designed in a stationary reference frame, and thus a PR current controller will be adopted in the inner control loop. As it will be shown in simulations and experiments, the proposed control scheme provides a good tracking and dynamic performance under step changes in the reference power. Moreover, the approach presented permit us to control the power injection not at the local connection point of the converter, but at the connection point of the line. This is due to the fact that the VF is implemented in such a way that the voltage in a remote point of the line can be estimated. In addition to the power control itself, this study could also benefit the frequency and the voltage regulation methods in distributed generation applications as for instance in microgrids.

The paper is structured as follows: in the first section, an overview of the proposed control methods is presented, which includes the explanation of the grid synchronization based on VF estimation, the effect of filtering configurations in the VF implementation, the inner loop control of the VSC and the current reference generation. It will be continued with the simulation and experimental results that shows a broad variety of testing scenarios, where the line impedance is changed and the power tracking at remote points offers a good performance.

\section{Proposed Control Method Based on VF for Power Converters with LCL Filters}

An overview of the system that will be considered as the study case in this work is shown in Figure 1. It should be noted that, as a difference with the previous works available in the literature (which are focused on the application of VF estimation in power converters equipped with LC or L connection filters), this paper deals with the control of a generic grid connected power converter through LCL filters. The LCL filter is by large the most extended grid connection filter due to the fact that it provides a good filtering response while optimizes the overall size and dimensions of the filter. Moreover, the point of synchronization in previous works is normally located at the primary 
of the transformer, $T_{1}$ as shown in Figure 1. As a difference, in this paper, the VF estimation point is considered to be after the transformer, $T_{2}$, which contributes to the uniqueness of this paper, as the grid impedance is also considered in the VF estimation.

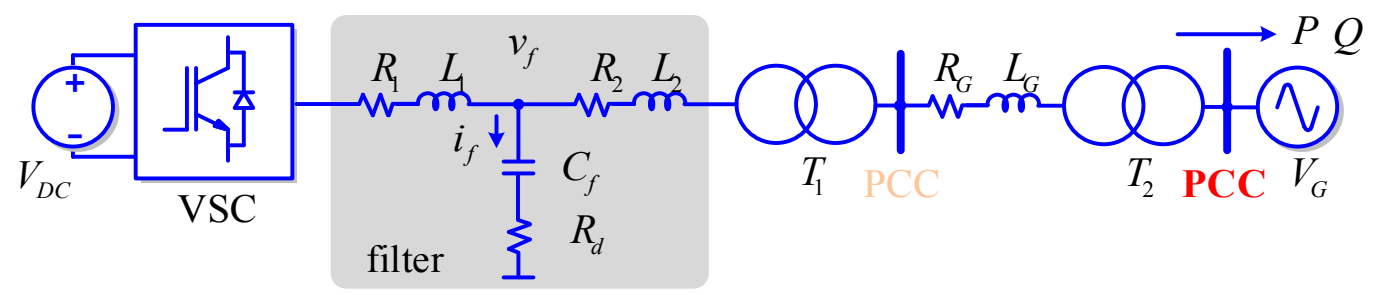

Figure 1. Overview of investigated system configurations.

The VF estimation enables to calculate the power at any point in the network and built controllers to regulate the active and reactive power delivery. Therefore, the VF estimation can regulate the active and reactive power not only at the output of the converter, but it is also possible to regulate the active and reactive power at the connection transformer that interfaces a plant with the main grid. Normally the connection point with the electrical company is far away from the converter. In this point, it is necessary to guarantee the cos phi required by the electrical company in many cases, hence the control proposed in this paper permits to regulate the active and reactive power delivery in a remote point. The fact of controlling the power in a remote point is relevant as the standards are asking to regulate the power at the connection point, which is not necessarily the output of the grid-side converter.

\subsection{Introduction to VF Estimation}

As mentioned in previous papers such as [7,8,16-18,22], a virtual flux, $\Psi$, can be obtained by integrating the converter output voltage, $V_{\text {conv }}$. Using basic modulation knowledge, the converter output voltage can be estimated easily by multiplying the pulse width modulation reference signal of the converter, $m_{r e f, \alpha \beta}$ with the DC-link voltage. However, the voltage drop caused by the conduction losses of the converter and the primary filter inductor, represented by the equivalent resistance $R_{1}$, should be taken into account for finding the converter output voltage before performing the integration. Considering that the flux calculation will be based in the stationary reference frame, $\alpha \beta$, the virtual flux can be calculated as shown in Equation (1):

$$
\Psi_{\alpha \beta}(t)=\int V_{c o n v} d t+\Psi_{0}=\int m_{r e f, \alpha \beta}\left(\frac{V_{d c}}{2}\right) d t+\Psi_{0}
$$

The ideal integration shown in Equation (1) can be sensitive to drifts and offsets in the VF estimation. Therefore, a Dual Second Order Generalized Integrator based Quadrature Signal Generator (DSOGI-QSG) is used, which has a good filtering profile and permits obtaining quadrature signals.

It should be noted that the frequency input needed by the DSOGI-QSG used in this work is available from the Frequency Locked Loop (FLL) output. By using the FLL, the system will be adapted to the center frequency of the SOGI resonators and the overall DSOGI-QSG structure will be automatically adapted to the variations in the grid frequency. The combination of the DSOGI-QSG with the FLL is known as DSOGI-FLL and it was extensively presented in [3].

\subsection{Grid Synchronization by Using DSOGI-FLL}

As mentioned earlier, the model of the synchronization method used in both simulation and experimental studies is based on the DSOGI-FLL. The DSOGI-FLL is suitable, as it provides a set of orthogonal signal $v-q v$ with no need of using any phase angle to synchronize the input signal. Only one FLL is required in the VF estimation since both SOGIs are working at the same frequency. 
The dual SOGI-QSG configuration considering the FLL as well as the Positive and Negative Sequence Components (PNSC) extractor is shown in Figure 2.

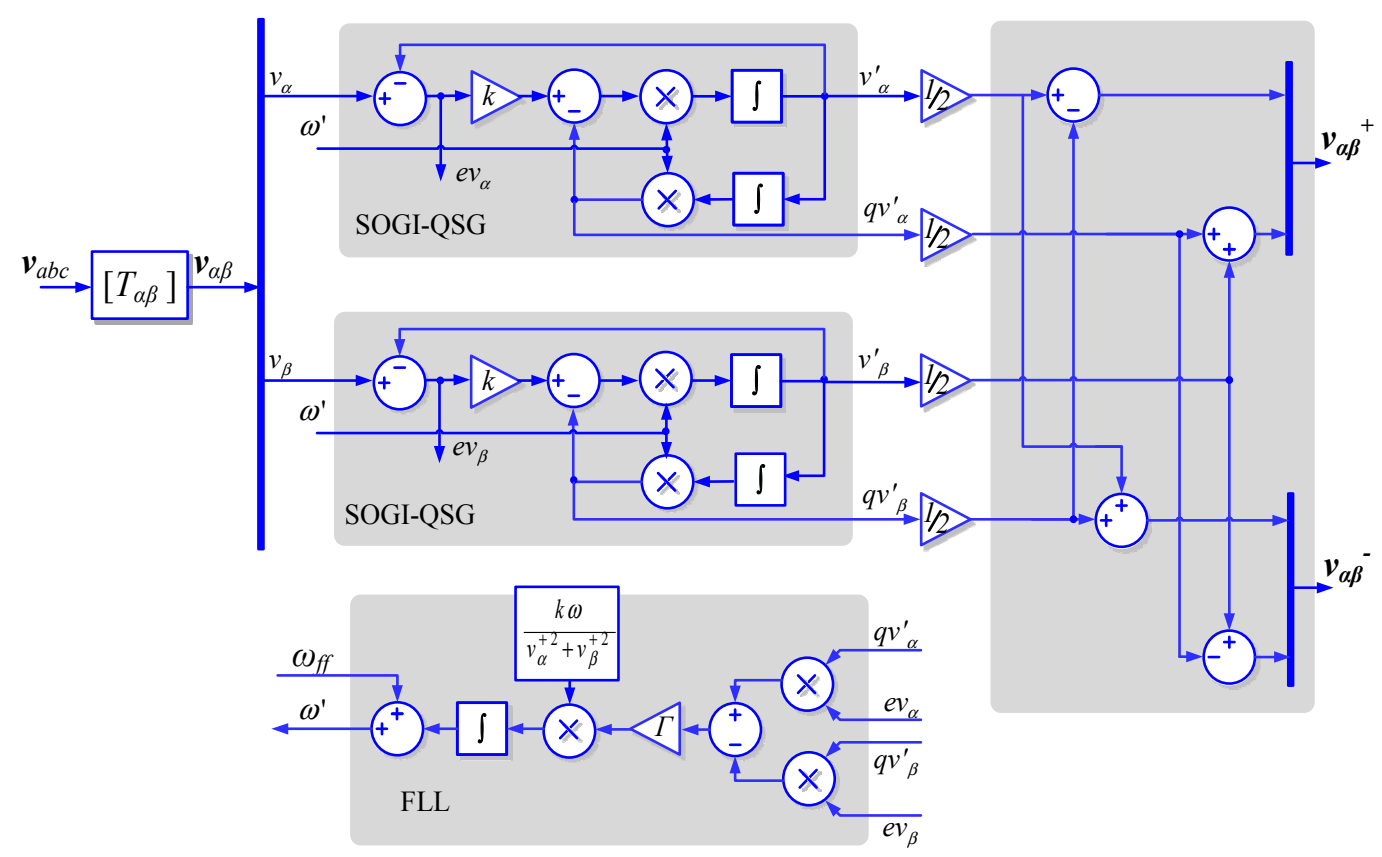

Figure 2. Basic structure of a dual second order generalized integrator-based quadrature signal generator with frequency locked loop and PNSC.

The configuration of the PNSC used in this work is the same configuration presented in [2]. Considering the SOGI-QSG block in Figure 2, the $v^{\prime}$ can be described as the direct output signal from the input signal $v$ whereas $q v^{\prime}$ represents the in-quadrature output signal from $v^{\prime}$, which is lagged $90^{\circ}$. The $q v^{\prime}$ is in fact an integral of the output $v^{\prime}$ multiplied with the frequency $\omega^{\prime}$. If the input $v_{\alpha}$ and $v_{\beta}$ are considered as the input signals, the direct output signal $v_{\alpha}{ }^{\prime}$ and $v_{\beta}{ }^{\prime}$ as well as the in-quadrature output signals, $q v_{\alpha}{ }^{\prime}$ and $q v_{\beta}{ }^{\prime}$ are the filtered components of the signals, where $v_{\alpha}{ }^{\prime}$ and $v_{\beta}{ }^{\prime}$ are in phase with $v_{\alpha}$ and $v_{\beta}$. Likewise, the in-quadrature output signals, $q v_{\alpha}{ }^{\prime}$ and $q v_{\beta}^{\prime}$ are lagged $90^{\circ}$ with respect to the $v_{\alpha}{ }^{\prime}$ and $v_{\beta}{ }^{\prime}$. Finally, $e v_{\alpha}$ and $e v_{\beta}$ are the error signals which are measured between the input $v$ and the direct output, $v^{\prime}$, for both $\alpha$ and $\beta$ components.

Assuming a constant resonance frequency, $\omega^{\prime}$, the transfer function of the direct output signal $v^{\prime}$ with respect to the input $v$ and the in-quadrature output signal $q v^{\prime}$ with respect to $v^{\prime}$ is given by Equations (2) and (3), respectively:

$$
\begin{aligned}
& \frac{v \prime}{v}(s)=\frac{k \omega / s}{s^{2}+k \omega / s+\omega \prime^{2}} \\
& \frac{q v \prime}{v}(s)=\frac{k \omega \prime^{2}}{s^{2}+k \omega / s+\omega \prime^{2}}
\end{aligned}
$$

The frequency response of the previous transfer functions are shaped by the value of the gain constant, $k$. Selecting the gain constant, $k=\sqrt{2}$ we obtain a good trade-off between overshoot and stabilization time. Therefore, $k=\sqrt{2}$ will be used in both simulation and experimental analysis in this work. The resulting frequency characteristics of the SOGI-QSG are shown in the Bode diagram depicted in Figure 3. 


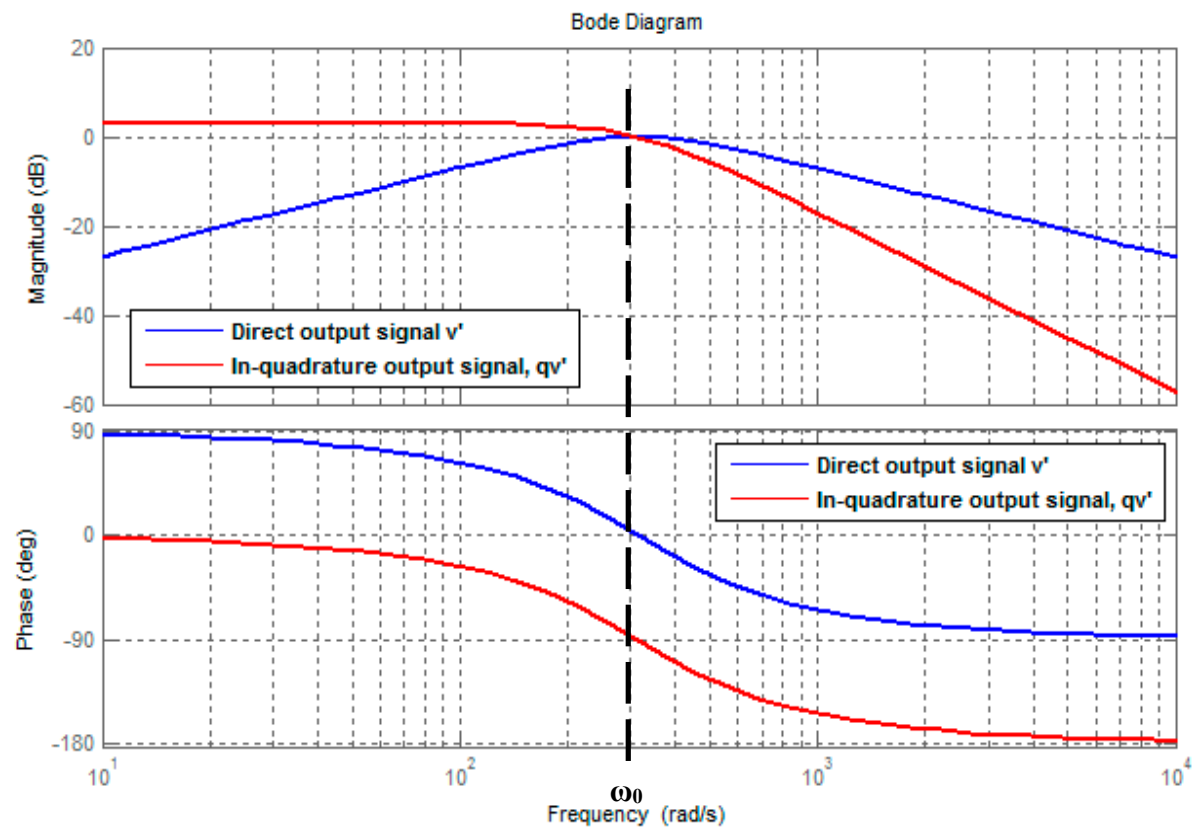

Figure 3. Bode diagram of SOGI-QSG block.

By referring to the transfer function stated in Equation (2) and the frequency responses shown in Figure 3, it can be clearly concluded that the direct output voltage $v^{\prime}$ has band pass characteristics with unitary gain and zero phase shift at the fundamental angular frequency, $\omega_{0}$. On the other hand, the transfer function stated in Equation (3) as well as the frequency response of the in-quadrature signal, $q v^{\prime}$ shown in Figure 3 has a low pass characteristic with unitary gain and $-90^{\circ}$ phase shift at the fundamental frequency.

\subsection{Implementation of VF Estimation with LCL Filter}

The VF estimation is based on the current measurement at the converter side, $I_{\text {conv }}$. The three phase quantities of the converter output current are transformed into the alpha-beta domain, as shown in Equation (4):

$$
\left[\begin{array}{c}
I_{c o n v, \alpha} \\
I_{c o n v, \beta}
\end{array}\right]=\sqrt{\frac{2}{3}} \cdot\left[\begin{array}{ccc}
1 & -1 / 2 & -1 / 2 \\
0 & \sqrt{3} / 2 & -\sqrt{3} / 2
\end{array}\right] \cdot\left[\begin{array}{c}
I_{c o n v, a} \\
I_{c o n v, b} \\
I_{c o n v, c}
\end{array}\right]
$$

Throughout this analysis, the converter current will be denoted as $I_{c o n v} \alpha \beta . V \int_{\alpha \beta}$ is the compensated converter output voltage, which is found considering the subtraction of the resistive voltage drop at $R_{1}$ from the converter's output voltage. The compensated converter output voltage is given by Equation (5):

$$
v^{\int}{ }_{\alpha \beta}(t)=\left[\left(m_{r e f} \alpha \beta \cdot v_{D C}\right)-\left(r_{1} \cdot i_{\text {conv }} \alpha \beta\right)\right] d t
$$

Moreover, since the power converter includes an LCL filter at the output, the capacitor current should be taken into account. Hence, it will be estimated and denoted as $I_{c f}^{\alpha \beta}$. In this work, the capacitor current has been estimated using the estimated capacitor voltage, $V_{c f} \alpha \beta$. Considering the use of per unit frequency, $\omega_{p u}$ in the estimation, the capacitor voltage in $\alpha \beta$ components can be obtained as shown in Equations (6) and (7), respectively:

$$
\begin{aligned}
& v_{c f}^{\alpha}(t)=\left(\left(v^{\int} \alpha\right) d t \cdot\left[\left(\omega_{p u} \cdot l_{1}\right) \cdot\left(i_{\text {conv }}^{\beta}(t)\right)\right]\right) \\
& v_{c f}{ }^{\beta}(t)=\left(\left(v^{\int} \beta\right) d t \cdot\left[\left(\omega_{p u} \cdot l_{1}\right) \cdot\left(i_{\text {conv }}{ }^{\alpha}(t)\right)\right]\right)
\end{aligned}
$$


Figure 4 shows the block diagram that permits to obtain the compensated converter output voltage and the capacitor voltage in $\alpha \beta$.

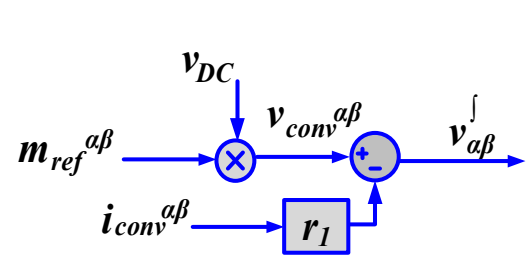

(a)

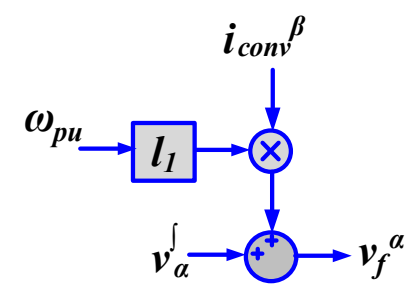

(b)

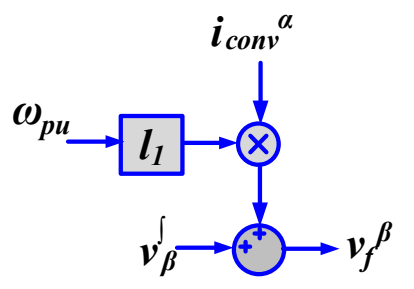

Figure 4. (a) Estimation of converter output voltage and compensation of voltage drop at $R_{1}$; (b) Estimation of capacitor voltage.

The compensated converter output voltage, $V^{\int}{ }_{\alpha \beta}$ in Figure $4 \mathrm{a}$ will be used later in the integration in order to obtain the VF estimation in both positive and negative sequence. The estimation of the capacitor voltage shown in Figure $4 \mathrm{~b}$ is essential for obtaining the capacitor current, since the proposed system is based on estimation and voltage sensorless measurements. The estimation of the capacitor current based on the estimated capacitor voltage is shown in Figure 5.

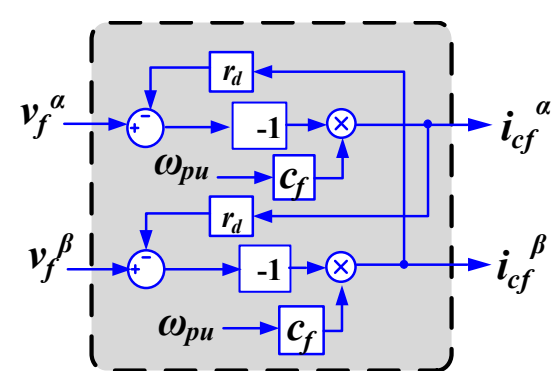

Figure 5. Estimation of the capacitor current based on the estimated capacitor voltage.

In Figure 6, the sequence separation of the converter and the integral of the grid current are presented. In order to obtain the positive and negative sequence of converter current and also to perform the integral of the grid current, four SOGI-QSG are used, where the frequency value comes from the FLL.

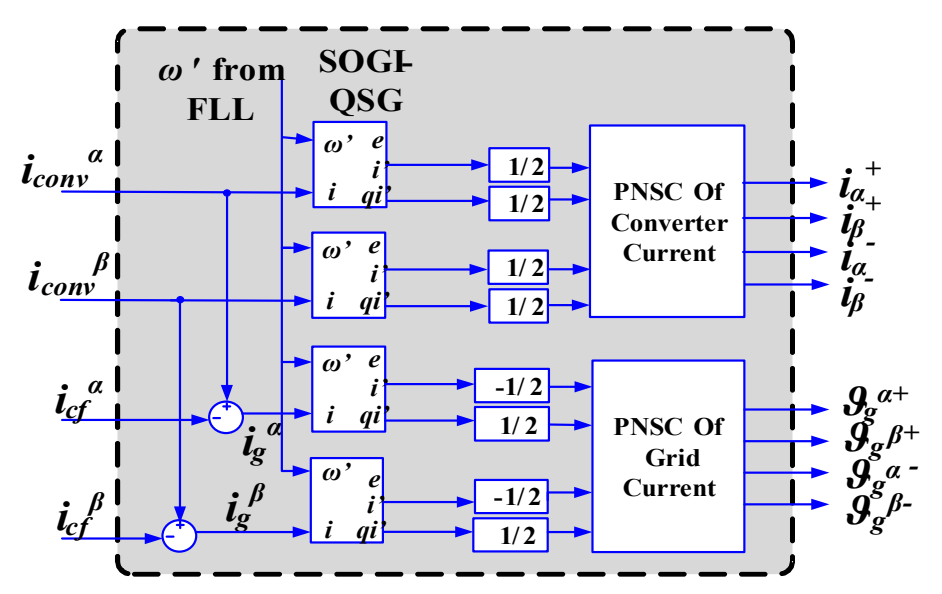

Figure 6. Sequence separation of converter currents and the grid current integral. 
The virtual flux after considering the per unit values can be expressed as $\chi$. The positive and negative sequence of the virtual flux is shown in Figure 7.

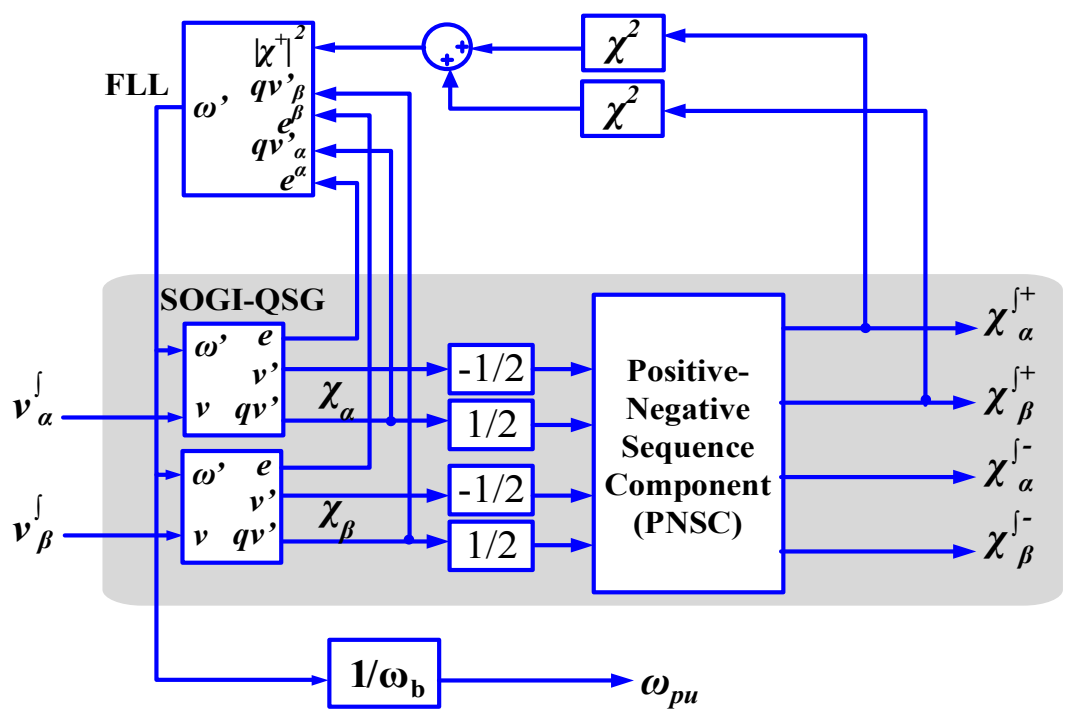

Figure 7. Positive \& negative sequence of virtual flux.

As it can be seen in Figure 7, the DSOGI-FLL is used to perform the estimation of the flux. The $90^{\circ}$ phase shifted for the sequence separation is available from the direct output, $v^{\prime}$ of the SOGI-QSG. Considering that the output is the derivative of $\mathrm{VF}$, a change in the sign will be equal to a $90^{\circ}$ phase lag. The per unit positive sequence VF components can be calculated by using the equation stated in Equations (8) and (9):

$$
\begin{aligned}
& \chi_{\alpha}^{+}(s)=\frac{1}{2} q v \prime_{\alpha}(s)+\frac{1}{2} v \prime_{\beta}(s) \\
& \chi_{\beta}^{+}(s)=\frac{1}{2} q v \prime_{\beta}(s)+\frac{1}{2} v \prime_{\alpha}(s)
\end{aligned}
$$

The inductive flux drop has been subtracted from the integrated voltage. Without considering the positive and negative sequence separation, the virtual flux estimation at the filter capacitor can be found using Equation (10). The Equation (10) can be simplified, giving rise to a simple time domain Equation (11):

$$
\begin{gathered}
\chi_{c}^{\alpha \beta}(t)=\underbrace{\left[\int\left(m_{r e f}^{\alpha \beta} \cdot v_{d c}-r_{1} \cdot i_{c o n v}^{\alpha \beta}(t)\right)\right]}_{\chi_{\alpha \beta}^{\int}}-l_{1} \cdot i_{c o n v}^{\alpha \beta}(t) \\
\chi_{c}^{\alpha \beta}(t)=\chi_{\alpha \beta}^{\int}(t)-l_{1} \cdot i_{c o n v}^{\alpha \beta}(t)
\end{gathered}
$$

where $\chi_{\alpha \beta}$ is the DSOGI-VF estimation. The positive and negative sequence of the capacitor current can be obtained based on the positive and negative sequence of the VF estimation at the filter capacitor. The VF estimation at the filter capacitor can be calculated by subtracting the induced flux drop at

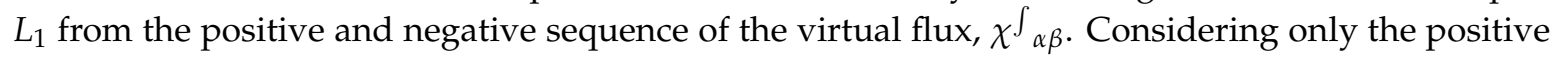
sequence component, Figure 8 shows the block diagram to obtain the positive sequence of the capacitor current from the positive sequence of the VF estimation at the capacitor. 


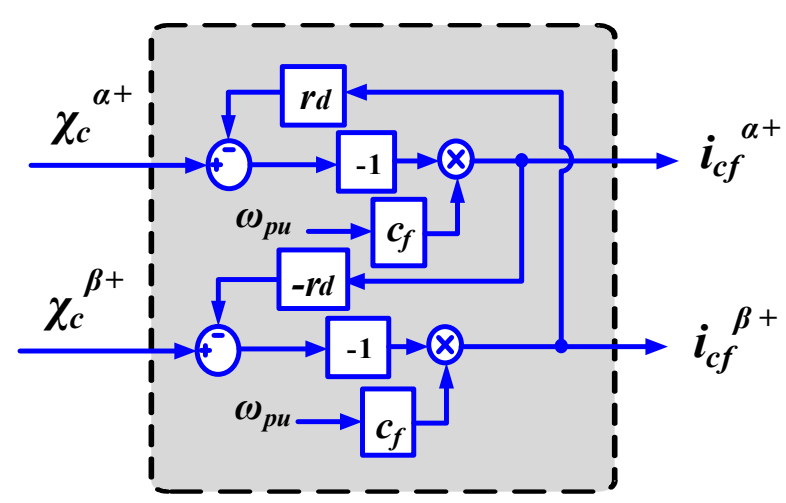

Figure 8. Estimation of positive sequence of capacitor current.

The voltage drop at the grid side is determined by multiplying the added value of $R_{2}$ and $R_{g}$ with the integral of the grid current, $\vartheta_{g}{ }^{\alpha \beta}$. The inductive fluxes drop at the grid side have been considered by multiplying the grid current by the addition of $L_{2}, L_{T 1}, L_{g}$ and $L_{T 2}$. The values of $L_{T 1}$ and $L_{T 2}$ are the $3 \%$ of the transformer base impedance, namely $Z_{T 1}$ and $Z_{T 2}$ (the rated power of the transformer $T_{1}$ and $T_{2}$ are $20 \mathrm{kVA}$ ). The resulting positive sequence VF estimation at the grid side in the stationary reference frame, considering the configuration shown in Figure 1, is given by Equation (12):

$$
\chi_{g}^{\alpha \beta+}(t)=\chi_{c}^{\alpha \beta+}(t)-\left(r_{2}+r_{g}\right) \cdot \vartheta_{g}^{\alpha \beta+}(t)-\left(l_{2}+l_{T 1}+l_{g}+l_{T 2}\right) \cdot i_{g}^{\alpha \beta+}(t)
$$

where

$$
i_{g}^{\alpha \beta+}=i_{\text {conv }}^{\alpha \beta+}-i_{c f}^{\alpha \beta+}
$$

The positive sequence coming from the virtual flux estimation at the grid side in Equation (13) is shown graphically in Figure 9.

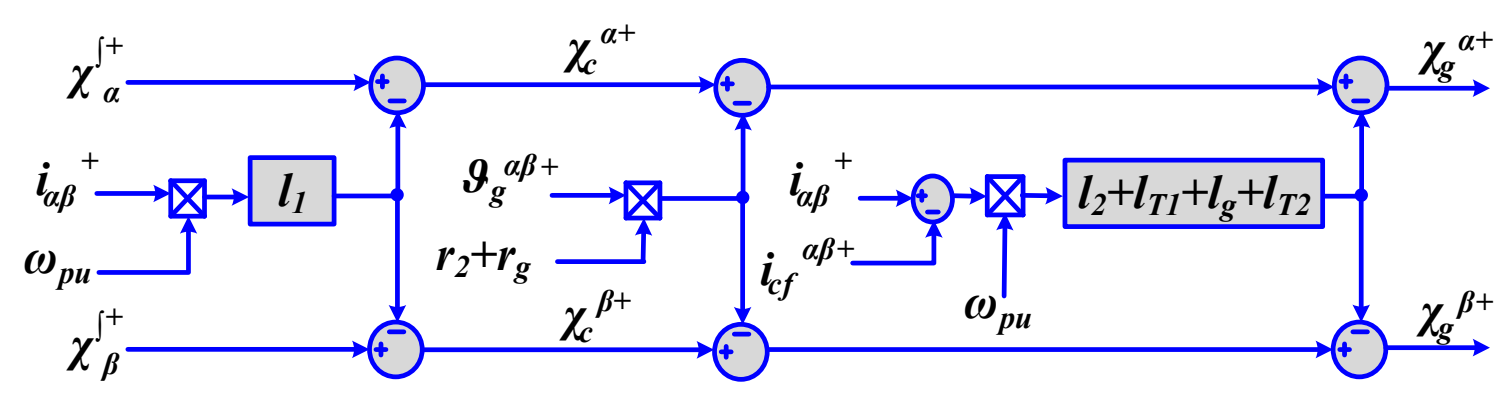

Figure 9. Virtual flux estimation at the grid side.

As a reference, the resulting VF estimation at the point of synchronization, which is after the transformer $T_{1}$, is given by (14):

$$
\chi_{g}^{\alpha \beta+}(t)=\chi_{c}^{\alpha \beta+}(t)-\left(r_{2}\right) \cdot \vartheta_{g}^{\alpha \beta+}(t)-\left(l_{2}+l_{T 1}\right) \cdot i_{g}^{\alpha \beta+}(t)
$$

The active and reactive power measurement for both simulation and experimental are based on Equations (15) and (16). Only the positive sequence of the VF estimation at the grid side is used since the system will be tested in balanced condition in this study case:

$$
\begin{gathered}
p=\chi_{g}{ }^{\alpha+} \cdot i_{\beta}-\chi_{g}{ }^{\beta+} \cdot i_{\alpha}=-\chi \perp \cdot i \\
q=\chi_{g}{ }^{\alpha+} \cdot i_{\alpha}-\chi_{g}{ }^{\beta+} \cdot i_{\beta}=\chi \cdot i
\end{gathered}
$$


where $\perp$ is denoted a set of signals that are lagging the original ones $90^{\circ}$ [16].

\subsection{Effect of Filtering Configuration in the VF Implementation}

As it has been previously mentioned, this work contributes to the actual state of the art by means of designing an application oriented to LCL filter-based configurations, which is broadly extended in the industry. In this paper, a passive damping has been considered for the LCL filter and hence damping resistors are placed in series with the capacitor branch [23]. Considering the per phase model of the LCL filter shown in Figure 1, the transfer functions considering two scenarios: with and without the damping resistor are given by Equations (17) and (18):

$$
\begin{gathered}
G_{F, d}(s)=\frac{C_{f} R_{d} s+1}{L_{1} C_{f} L_{2} s^{3}+C_{f}\left(L_{1} L_{2}\right) R_{d} s^{2}+\left(L_{1}+L_{2}\right) s} \\
G_{F}(s)=\frac{1}{L_{1} C_{f} L_{2} s^{3}+\left(L_{1}+L_{2}\right) s}
\end{gathered}
$$

The damping resistor has been included in the design to smoothen the spike that appears when considering the filter transfer function with only inductive and capacitive elements in Equation (18). In order to have a more realistic approach the damping resistor will be considered as a former element in the study case from now on. The LCL-filter parameters and other operating nominal values used for both simulation and experimental studies are listed in Table 1.

Table 1. System parameters.

\begin{tabular}{ccc}
\hline Abbreviation & Nomenclature & Values \\
\hline$S_{N}$ & Rated Apparent Power & $10 \mathrm{kVA}$ \\
$V_{g}(p-p)$ & Phase to Phase Grid Voltage & $400 \mathrm{~V}$ \\
$V_{g}(p)$ & Phase Voltage & $230 \mathrm{~V}$ \\
$V_{D C}$ & DC-Link Voltage & $700 \mathrm{~V}$ \\
$L_{1(a b c)}$ & Inductor, $L_{1}$ & $3.4 \mathrm{mH}$ \\
$L_{2}(a b c)$ & Inductor, $L_{2}$ & $0.588 \mathrm{mH}$ \\
$L_{g(a b c)}$ & Grid Inductance, $L_{g}$ & $10 \mathrm{mH}$ \\
$C_{f(a b c)}$ & Filter Capacitor & $4.7 \mu \mathrm{F}$ \\
$R_{d(a b c)}$ & Damping Resistor & $1.8 \Omega$ \\
$f_{s w} \& f_{s}$ & Switching \& Sampling Frequency & $10 \mathrm{kHz}$ \\
\hline
\end{tabular}

\subsection{Inner Loop Control of VSC}

The inner loop control of a VSC is normally a current controller. Current controllers can be categorized into two categories which are the linear type controller and the non-linear type controller. The most popular linear current control techniques used until now are the Proportional Integral (PI) current controller, where the control is performed in a rotational reference frame. The other one is the Proportional Resonant (PR) current controller, which is used to track a sinusoidal set point working in a static reference frame. In this work, a PR current controller will be used to accommodate the inner loop control of the VSC. The selection is supported by the fact that the PR current controller offers a very good performance and its implementation is simple. An ideal PR controller is described in Equation (19) however, it may give stability problem due to its infinite gain [24]:

$$
G_{P R}(s)=K_{p}+K_{r} \frac{s}{s^{2}+\omega_{o}^{2}}
$$

In order to avoid this condition, the PR controller can be made as non-ideal, considering a damped or bandpass structure. The resulting transfer function is given by Equation (20): 


$$
G_{P R}(s)=K_{p}+K_{r} \frac{2 \omega_{c} s}{s^{2}+2 \omega_{c} s+\omega_{o}^{2}}
$$

The term $\omega_{c}$ is the bandwidth around the ac frequency of $\omega_{0}$. The gain of the PR controller at the frequency $\omega_{0}$ in Equation (20) is finite, but it is still large enough to provide only a very small/null steady state error. This equation makes the controller easy and reliable when it is digitally implemented in real applications. In the previous equations $K_{p}$ is the proportional gain and $K_{r}$ is the resonant gain term. The ideal resonant provides an infinite gain at the ac frequency $\omega_{0}$ and no phase shift and gain at the other frequencies. Considering the transfer function in Equation (19), the bandwidth is very small and almost null if compared to the non-ideal cases in Equation (20), where the $\omega_{c}$ can be widened or narrowed to control the bandwidth. The smaller the value of $\omega_{c}$, the more sensitive the filter to the frequency variations and it will also lead to a slower transient response. Normally, a reasonable value of $\omega_{c}$ used in practice is between 5-15 rad/s. In this controller it is also possible to control the bandwidth by using the $K_{r}$ value. The higher the values of $K_{r}$, the larger the bandwidth can be.

On the contrary, the lower the value of $K_{r}$, the narrower is the bandwidth. On the other hand, by varying the value of $K_{p}$, it will affect the magnitude. The magnitude increases with $K_{p}$ but the peak value is still at the resonant frequency. The output of the PR current controller is the reference voltage at both $\alpha$ and $\beta$ component. The modulation index, $m_{r e f, \alpha}$ and $m_{r e f, \beta}$ used in the VF estimation can be obtained by dividing the reference voltage by the $V_{D C}$. This modulation index will be transformed into the $a b c$ reference frame.

\subsection{Current Reference Generated for PR Current Controller}

In addition to the current controller and the VF estimation, it is necessary also to calculate the set point to be provided to the current controller. The current set point, which is normally known as current reference, is the output generated by the outer loop controller. The current reference generation is based on the power calculation where the active and reactive power reference are also required. The positive sequence of the VF estimation at both alpha and beta components will be used to calculate the current reference. Since the current is controlled at the converter side, the capacitor current needs to be added with the current at PCC in order to match with the current at the converter side. The current references in the alpha and beta reference frame can be calculated in Equations (21) and (22):

$$
\begin{aligned}
& i_{\alpha}^{*}=\left[\frac{P_{r e f} \cdot \chi_{g}{ }^{\alpha+}+Q_{r e f} \cdot \chi_{g}{ }^{\beta+}}{\chi_{g}{ }^{\alpha+2}+\chi_{g}{ }^{\beta+2}}\right]+i_{f}{ }^{\alpha} \\
& i_{\beta}^{*}=\left[\frac{P_{r e f} \cdot \chi_{g}{ }^{\beta+}+Q_{r e f} \cdot \chi_{g}{ }^{\alpha+}}{\chi_{g}{ }^{\alpha+2}+\chi_{g}{ }^{\beta+2}}\right]+i_{f}^{\beta}
\end{aligned}
$$

\section{Simulation Results}

Based on the system overview shown in Figure 1, the complete proposed method used for performing both the simulation and experimental analysis is shown in Figure 10. The system parameters listed in Table 1 are the ones used for both simulation and experimental studies. Considering the parameters listed in Table 1 and the proposed method shown in Figure 10, the simulation have been done considering different scenarios. 


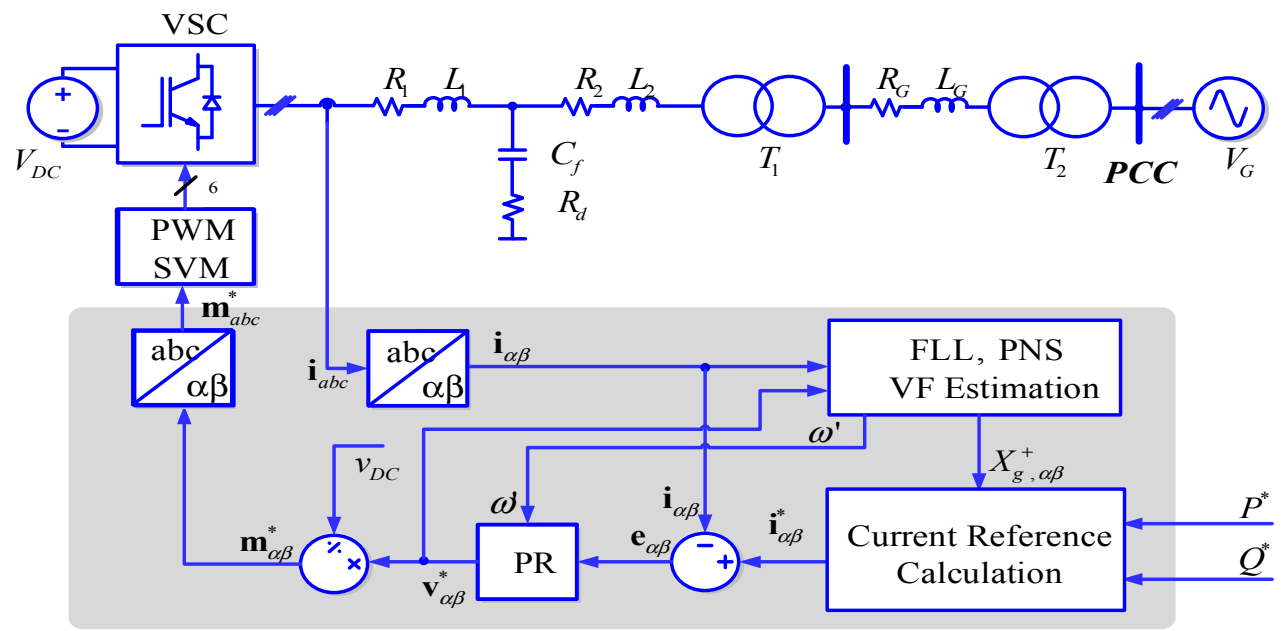

Figure 10. Structure of the study case considered for the simulation and the experimental validation.

\subsection{Change in Active Power Delivery at the Point after $T_{1}$ and PCC}

In order to evaluate the controllability of the control proposal, the first test is oriented to evaluate the performance of the system when tracking the active power after the point $T_{1}$, while the second test is focused on evaluating the performance of the system after the point of $T_{2}$ which is also the PCC according to Figure 1. The first test will permit to ensure that the system is working properly before the entire system is simulated. The reference step changes has been made and the results for the first test considering the per-unit values are shown in Figure 11.

(a)

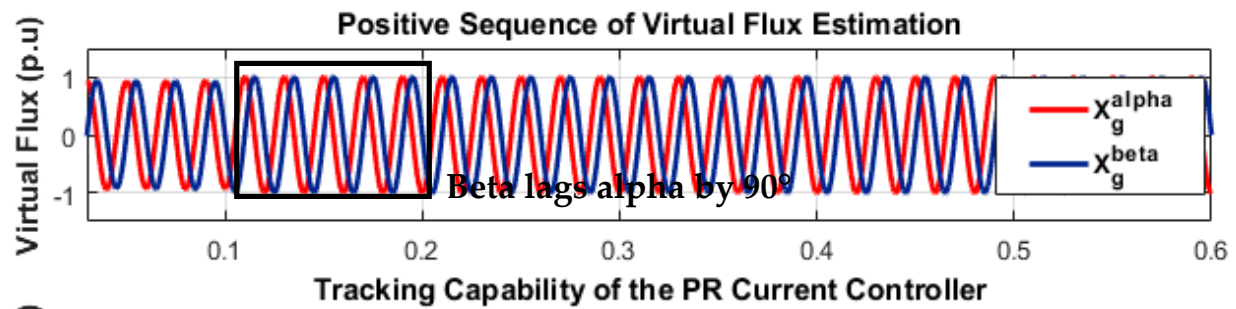

(b)

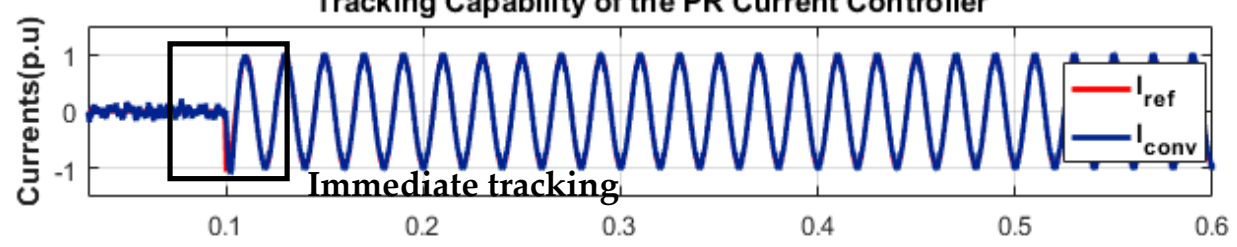

(c)

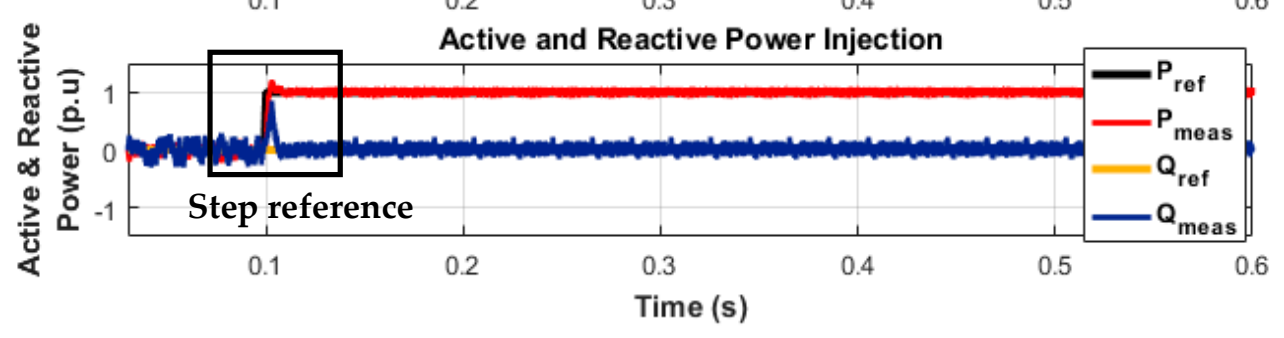

Figure 11. Simulation results: (a) Positive sequence of VF estimation after transformer, $T_{1}$; (b) Tracking capability of the system of the current controller; (c) Active \& reactive power injection to the grid.

The power reference step is performed at $t=0.1 \mathrm{~s}$. The system is simulated from $t=0.1 \mathrm{~s}$ until $t=0.6 \mathrm{~s}$. The proportional gain, $K_{p}$ and the resonant gain $K_{r}$ used in the simulation are set to 7 and 19 respectively. The plots in Figure 11a shows the positive sequence of the VF estimation after the transformer $T_{1}$. This simulation proves that the voltage sensor-less system is working well, as the positive sequence VF estimations have been obtained with no need of measuring the grid voltage. 
The alpha and beta component of VF estimation have the same amplitude of the beta component but lagged $90^{\circ}$, what endorses the VF calculations. In this simulation study, the PR current controller used in the inner loop provides a very fast and good response. In fact the converter current is able to follow the reference very fast, as it is shown in Figure $11 \mathrm{~b}$. The active power reference, $P_{\text {ref }}$ has been set to 1 p.u $(10 \mathrm{~kW})$ while the reactive power reference, $Q_{\text {ref }}$ is set to zero. In the Figure $11 \mathrm{c}$, it can be seen that the measured active power and the reactive power match both the power references.

The second test is focused on testing the remote power control. Since the VF estimation in this test is considered after the transformer $T_{2}$, it is important to make sure that the output of the VF estimation is perfect without any phase displacement. The power reference step applied in this simulation is performed at $t=0.1 \mathrm{~s}$ and the power is stepped down to zero at $t=0.4 \mathrm{~s}$ in order to observe the performance of the system during the transient as well as in the steady state. As in the first test, the active power reference, $P_{\text {ref }}$ has been set to $1 \mathrm{p} . \mathrm{u}(10 \mathrm{~kW})$ while the reactive power reference, $Q_{\text {ref }}$ is set to zero. The simulation results for the proposed system is shown in Figure 12.

(a)

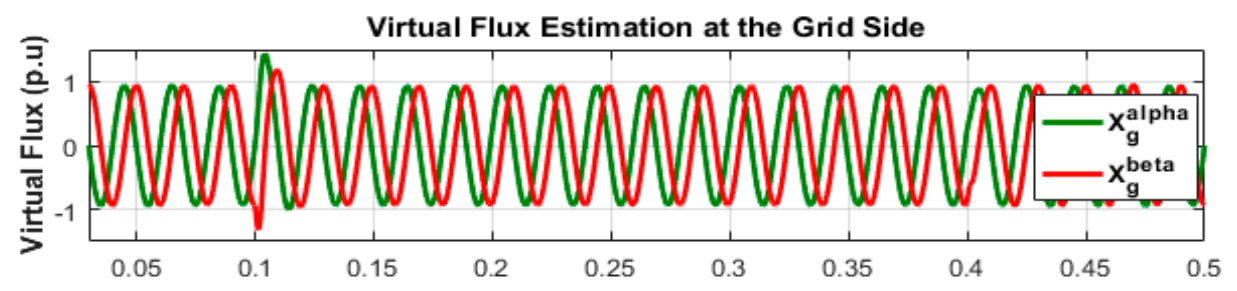

(b)

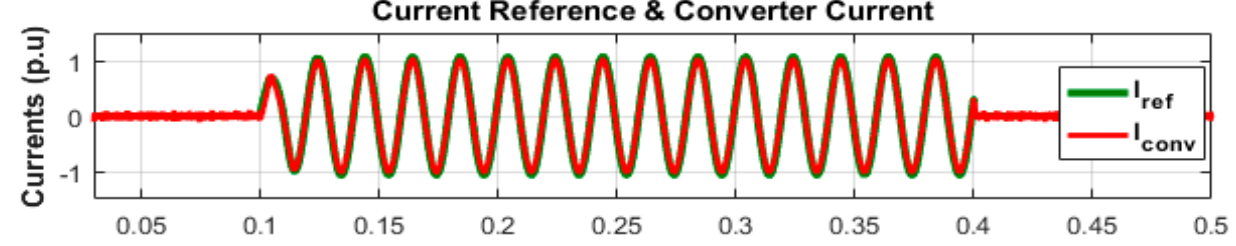

(c)

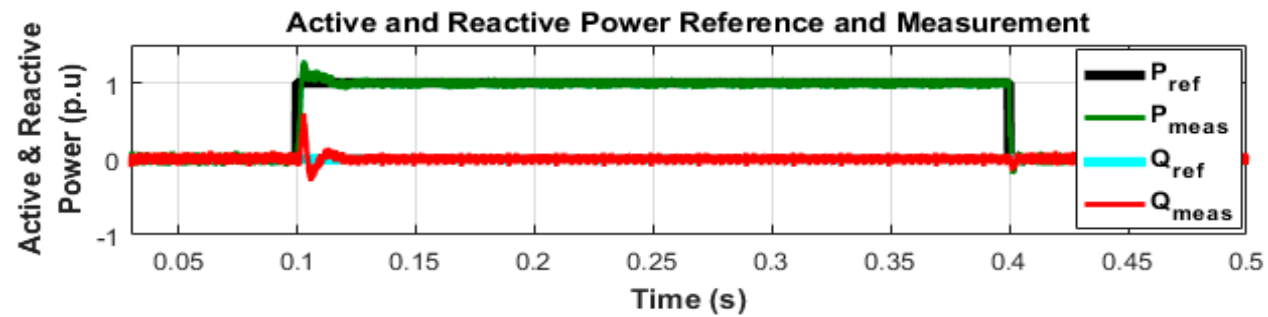

Figure 12. Simulation results: (a) VF estimation at the PCC; (b) Current reference generation and converter current; (c) Active \& reactive power reference and measurement.

Based on the simulation results obtained in Figure 12a, the estimated virtual flux positive sequence is able to properly estimate the grid voltage conditions. The finding highlights that the estimation performed by the DSOGI-VF works accurately, as the positive sequence components of the virtual flux matches quite well with the value of the line-to-line voltage of the grid. The current reference in this case is generated based on the output of the positive sequence of the VF estimation, as well as the active and reactive power references, that provide the instantaneous current to be tracked. The performance of the PR current controller is one of the important issues in this work because without a proper control, the tracking error will be attained during the steady state condition. However, based on the results shown in Figure 12b, it can be concluded that the performance of the proposed control is very good, as the converter current is able to follow the reference without any errors. By referring to the results shown in Figure 12, the proposed system is able to produce a good results as long as the required parameters are available during the estimation.

The measured active and reactive power are shown in Figure 12c. It can be concluded that the proposed system is able to properly control the power at the remote point. Based on the results shown 
in Figures 11c and 12c, a transient overshoot occurs when the step was applied at $t=0.1 \mathrm{~s}$. However, this overshoot is soon attenuated and the system reaches its steady state at $t=0.105 \mathrm{~s}$. However, this transient overshoot does not have a significant impact in the active and reactive power injection to the grid.

\subsection{Change in Active and Reactive Power Injection}

The performance of the system presented shown in Figure 1; when different values of active and reactive power should be delivered to the grid will be analysed in this subsection. For doing that so, different step changes in both active and reactive power have been applied in order to ensure that the system is able to control remotely the active and reactive power injection. The performance of the system in these scenarios are shown in Figure 13.

Different Reference Step Changes Applied to the Active and Reactive Power

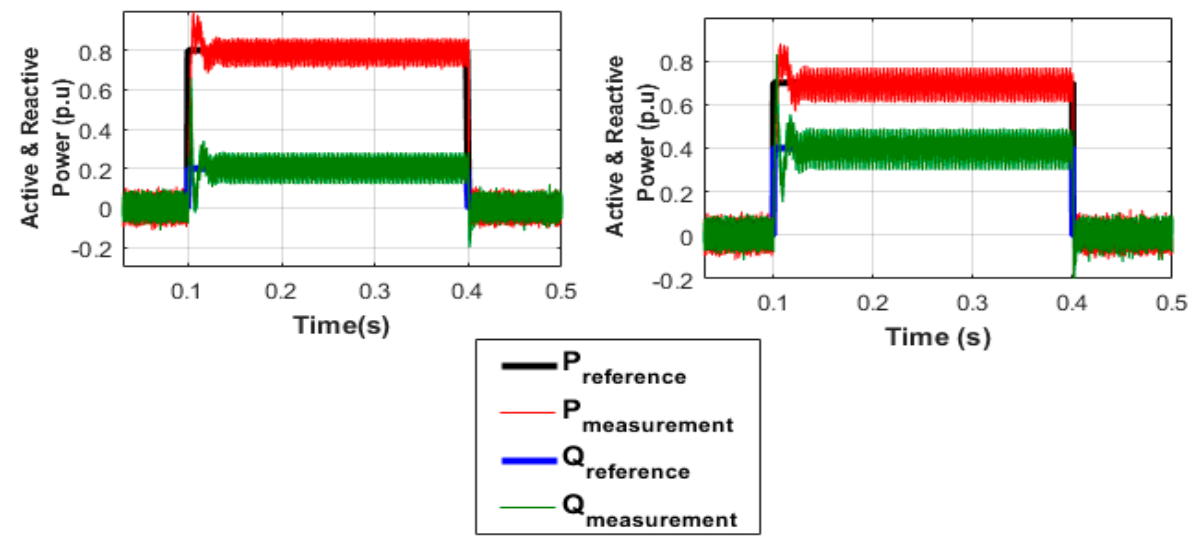

(a)

(b)

Figure 13. Different step changes in the active and reactive power reference. (a) Step change of 0.8 p.u in active and 0.2 p.u in reactive power; (b) Step change of 0.7 p.u in active and 0.4 p.u in reactive power.

In the first scenario, shown in Figure 13a, the active and reactive power reference have been set to 0.8 p.u and 0.2 p.u respectively. In the second scenario shown in Figure 13b, the active power has been set to 0.7 p.u and the reactive power reference have been set to 0.4 p.u.

Based on the results obtained, it can be concluded that in all cases the delivered active and reactive power match with the references. These results verify that the VF estimations obtained in Figure 12a are reliable to be used in the active and reactive power calculations. It should be noted that the simulation results shown in Figures 12 and 13 are based on a system with a grid inductance value of $10 \mathrm{mH}$.

\subsection{Change in Active and Reactive Power Injection Using Different Values of Grid Inductance}

A different scenario of active and reactive power injection has been captured in Figure 14, where different values of grid inductance of $10 \mu \mathrm{H}, 5 \mathrm{mH}$ and $10 \mathrm{mH}$ have been used. In all cases, the active power reference is set to $1 \mathrm{p} . \mathrm{u}$ and the reactive power reference is set to $0 \mathrm{p} \cdot \mathrm{u}$.

In the first scenario shown in Figure 14a, the grid inductance used is $10 \mu \mathrm{H}$. In the second and third scenarios shown in Figure 14b,c, the grid inductance values used in the simulation are $10 \mathrm{mH}$ and $5 \mathrm{mH}$ respectively. In real applications these values are mainly calculated from the impedance of the transformers and the effect of the cables, although the second one has a much lower influence.

Considering the results obtained in Figure 14, it can be concluded that the system has a good performance. All the results show a perfect tracking between the delivered active and reactive power and the corresponding references. The transient performance is also satisfactory in all cases, however, 
as expected, the lower the grid inductance used, the faster the settling time and steady state can be reached compared to the higher values of the grid inductance.

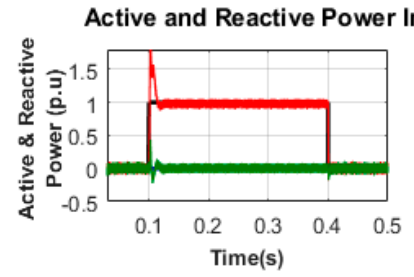

(a)
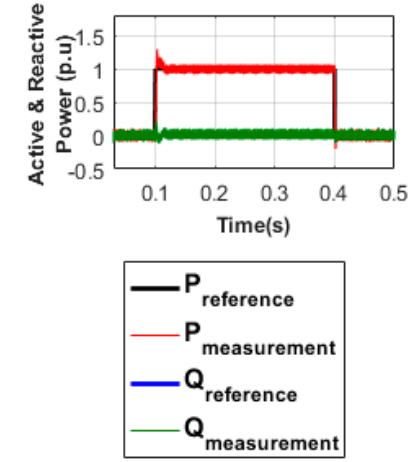

(b)

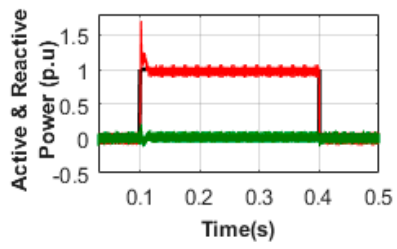

(c)

Figure 14. Different scenarios of active and reactive power injection: (a) When grid inductance, $L_{g}=10 \mu \mathrm{H}$; (b) When grid inductance, $L_{g}=10 \mathrm{mH}$; (c) When $L_{g}=5 \mathrm{mH}$.

\section{Experimental Results}

The experimental setup that will be used for the final validation consists of a $10 \mathrm{kVA}$ inverter which is connected to a controlled $230 \mathrm{~V}$ phase-to-phase (400 V line-to-line), $50 \mathrm{~Hz}$ three phase AC power source through the LCL filter. The inverter has been powered by a programmable dc power supply that provides a $700 \mathrm{~V}$ dc-link. The inverter, LCL filter and the transformer are located inside the converter cabinet and the output from the converter is linked to the input of the oscilloscope. The output of the oscilloscope then will be linked to the grid emulator-sag generator device, which supplied the grid voltage to the overall system. The proposed control method has been programmed on a dSpace1103 platform (dSPACE Inc., Wixom, MI, USA). The experimental setup in the lab is shown in Figure 15a and the block diagram of the setup is shown in Figure 15b, respectively.

As for the experimental investigation, the "grid emulator-voltage sag generator device" has been used for setting a grid inductance value of $10 \mathrm{mH}$. It is important to remark that the layout of the experimental setup has the same structure of the one used in the simulation analysis presented in the previous section. Moreover, in the experimental setup have the same parameters as the ones provided for the simulation, which are listed in Table 1 . In this workbench the active and reactive power references can be changed easily and the values of measured as well as estimated signals can be easily plotted and captured by using SCADA system which is built using the Control Desk application of dSpace.

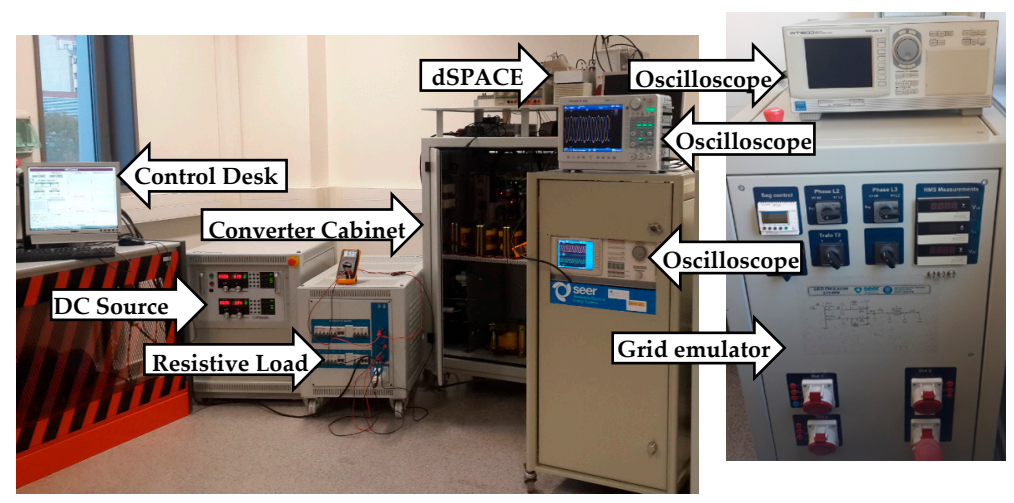

(a)

Figure 15. Cont. 


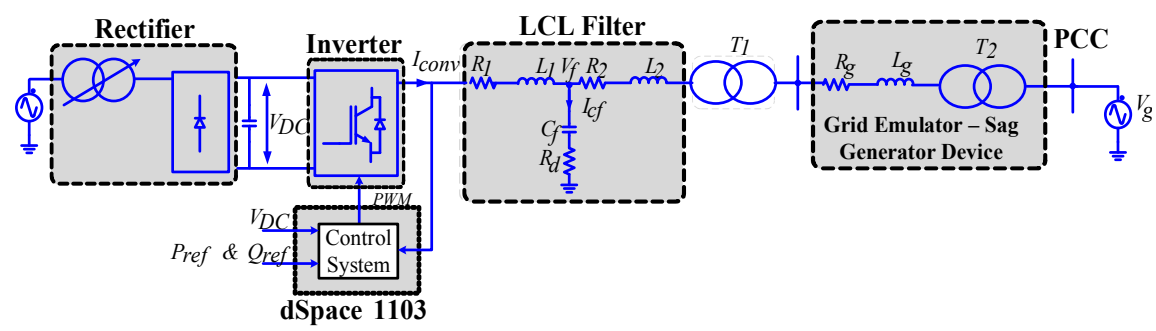

(b)

Figure 15. Experimental Setup: (a) Experimental setup in the lab; (b) Block diagram of the experimental setup.

\subsection{Performance of VF Based Controller}

The first step of the experimental validation will be focused on testing the performance of the VF based controller, which is now running on the dSpace. This first test will permit us to evaluate whether the digital implementation of the controller works properly or not. Since the proposed system has been tested in simulation, the experimental result obtained here permits to verify that the proposed method is working well also in a real platform. As it will be shown, the performance achieved is satisfactory and the pipeline of the controller is ensured working at the sampling frequency of the DSP which is embedded in the dSpace. A first test, where the value of the resonant controller is changed, is made in order to carry out a preliminary evaluation of the transient performance. This scenario can be observed in Figure 16a,b.

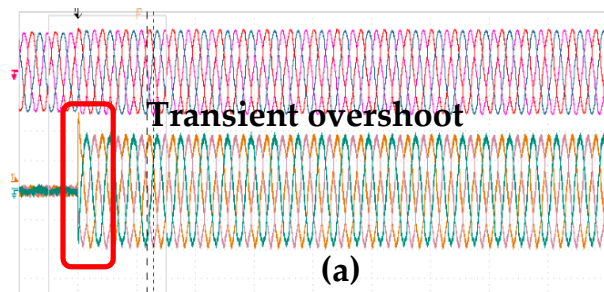

(a)

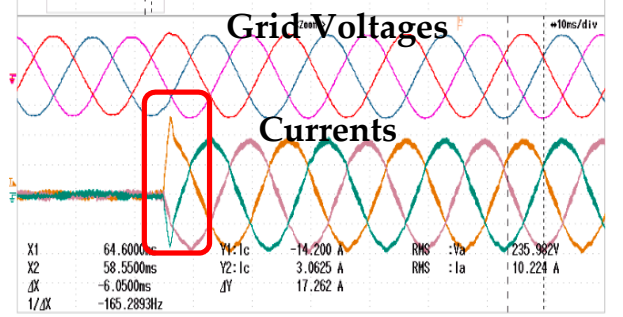

(b)
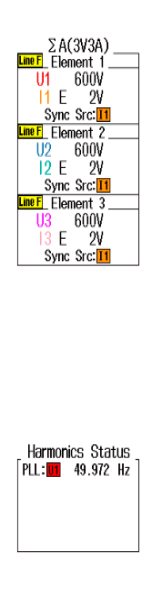

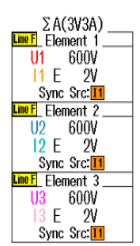

(c)

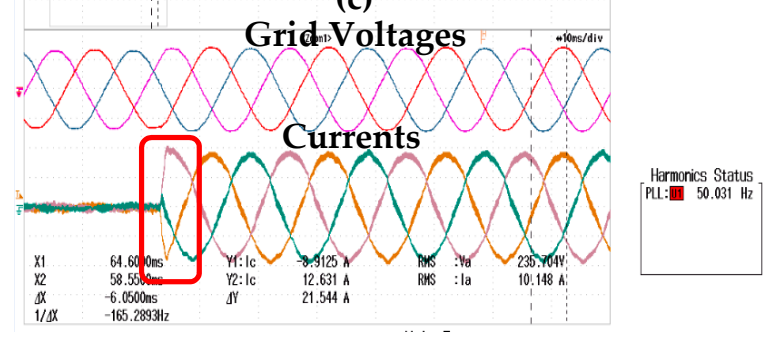

(d)

Figure 16. Experimental results captured from the oscilloscope: (a) Experimental results of grid voltages and current when $K_{p}=7$ and $K_{r}=70$; (b) Zoom in version of the grid voltages and currents shown in (a); (c) Experimental results of grid voltages and current when $K_{p}=7$ and $K_{r}=19$; (d) Zoom in version of the grid voltages and currents shown in (c).

The waveforms of grid voltages and currents have been captured when the reference power has been boosted up from zero to $7 \mathrm{~kW}\left(0.7\right.$ p.u). In Figure 16a,b, the $K_{p}$ and $K_{r}$ value has been set to 7 and 70 , respectively. When the step has been applied, there is a transient overshoot occurred on the current even though the system is stable in both open loop and closed loop. However, when the resonant gain is reduced for instance to 19, this transient overshoot is eliminated as shown in Figure 16c,d, improving thus the performance of the system. 
Another test has been carried out considering an active power reference step going from zero to $8 \mathrm{~kW}(0.8$ p.u), while the reactive power reference remains equal to zero. The experimental results obtained from are shown in Figure 17.
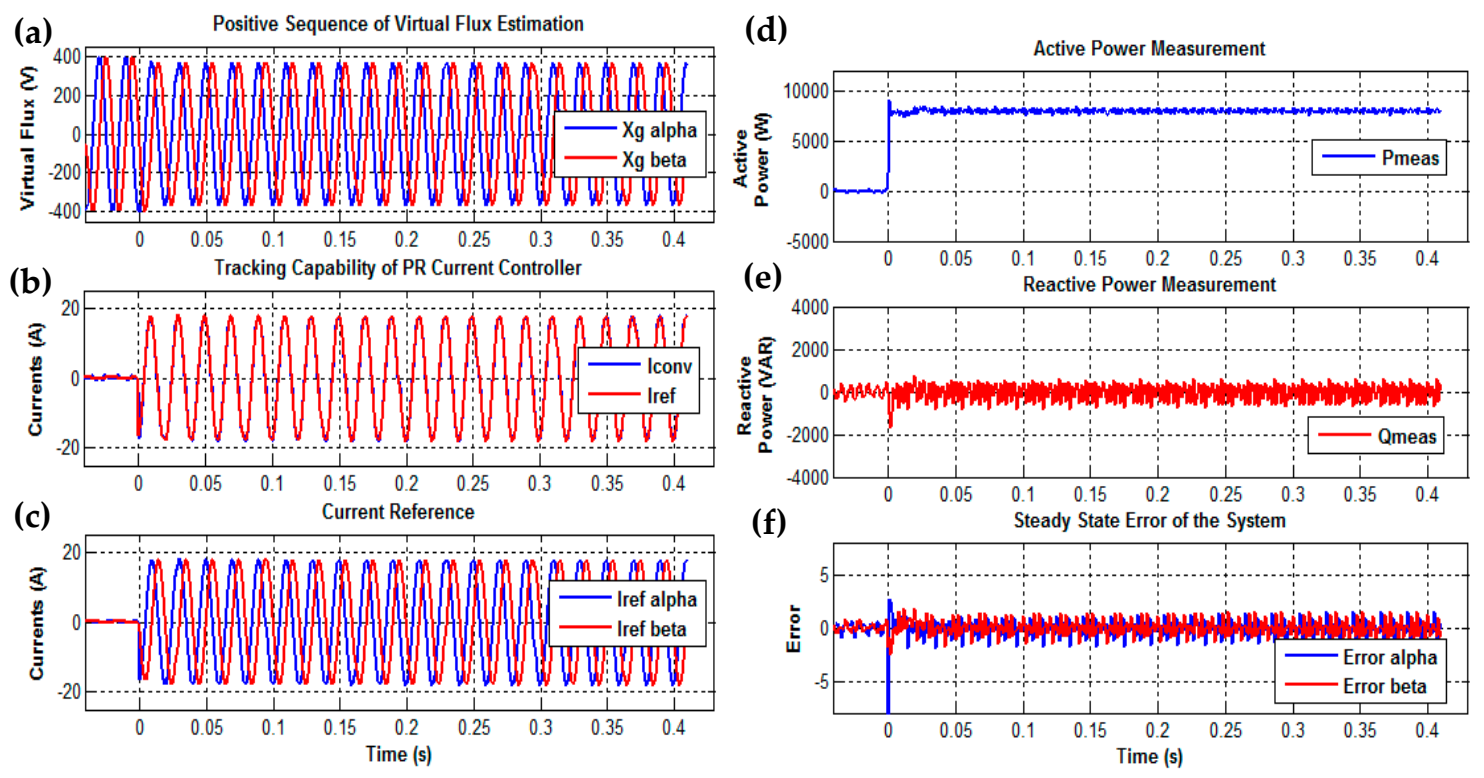

Figure 17. Active power change: (a) Positive sequence of virtual flux estimation; (b) Tracking capability of PR current controller; (c) Current reference generation; (d) Active power measurement; (e) Reactive power measurement; (f) Steady state error of the system.

The VF-based synchronization method works properly without measuring the grid voltage for the synchronization process. It is worth remarking that this verifies that the grid frequency supplied by the FLL can be estimated by using the virtual flux signal. Moreover, this estimation can be used with good performance at different control levels, as for instance, the PR current controller block.

Since the experimental is performed under balanced condition, it is clear that the positive sequence of the virtual flux estimation has the same amplitude, as shown in Figure 17a. The phase of the grid voltage in the case of VF based synchronization can be obtained by considering the inverse tangent of $\chi_{g}{ }^{\beta+} / \chi_{g}{ }^{\alpha+}$.

In this experimental validation, the virtual flux estimation provides good results. The $K_{p}$ and $K_{r}$ values are maintained to 7 and 19, respectively, in order to see if the values are reliable enough to be used in the digital system. Based on the results obtained, it can be seen that the tracking capability of the PR current controller is perfect, without any delay or phase displacement. The converter current in this case is able to follow the reference current generated, as shown in Figure 17b. Since the positive sequence virtual flux estimation output is balanced, the current reference used for the PR current controller is also balanced and has the same amplitude as shown in Figure 17c. It is clear that both active and reactive power measurements shown in Figure 17d,e match with the active and reactive power reference that have been set. In this work, the instantaneous power theory has been used to measure the active and reactive power, without including any filter. This is the reason why the power has a small ripple, due to the inherent noise in the acquisition system boosted also by the relatively high impedance of the experimental grid. In steady state conditions, the error in the $\alpha$ and $\beta$ components are zero as shown in Figure 17f, which proves that the PR current controller is efficient at eliminating the tracking error. 


\subsection{Control of Active Power Delivery}

As the main objective of this work is to control the active and reactive power injection remotely, monitoring the frequency and knowing the voltage magnitude at the point of connection are very important in order to ensure a secure operation of the whole system. Theoretically, in an electrical system, the magnitude of the voltage is controlled by the reactive power exchange. Based on the understanding that any mismatching between the supply and demand will give rise to a change of system voltage, the voltage gradient across the transmission line defines the reactive power flow to be injected or absorbed in the line and vice versa. This is the reason why the positive sequence VF estimation is so significant and important for controlling the reactive power remotely. In Figure 18, the results captured from the oscilloscope are shown when $9.5 \mathrm{~kW}(0.95 \mathrm{p} . \mathrm{u})$ are injected to the grid.

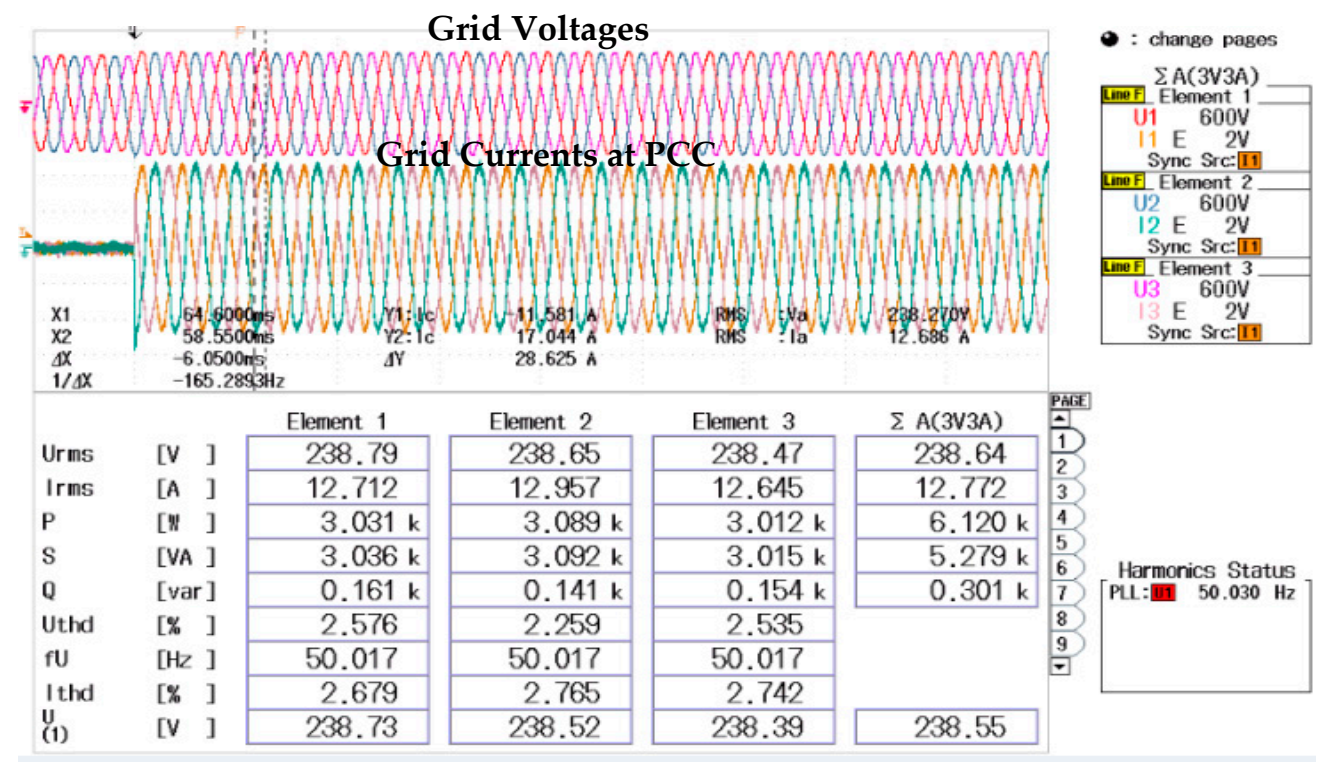

Figure 18. Experimental results captured from the oscilloscope.

The result shown in Figure 18 prove that the proposed system works properly. Since the frequency is the most important global magnitude in AC network, it should be ideally maintained by all the interconnected elements in a cooperative manner. It is understandable that in case of the frequency variations, regulating the active power is essential, increasing/decreasing the power when the frequency decreases/increases. In this work, the system frequency used is $50 \mathrm{~Hz}$. When the step reference has been applied, the system works well without any transient overshoot, as shown in Figure 19.
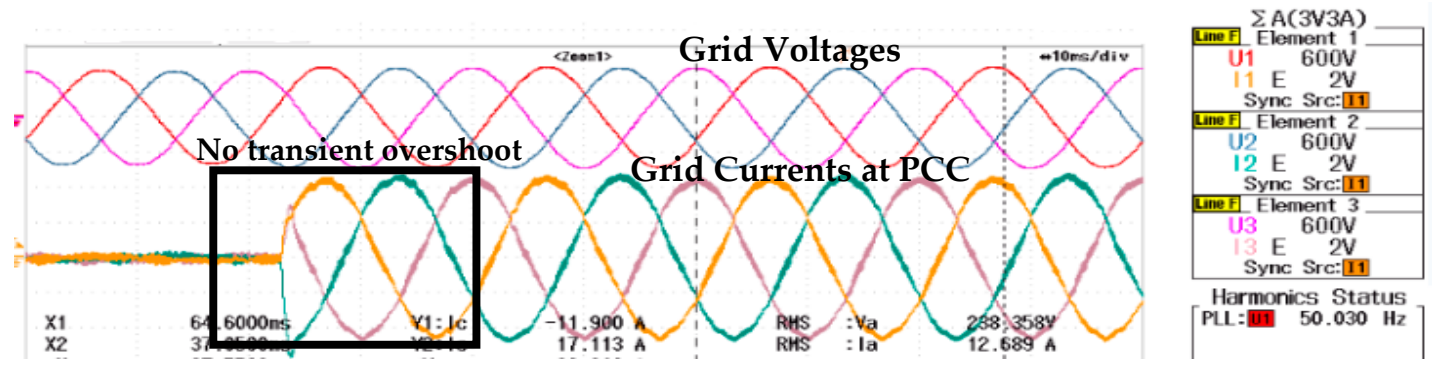

Figure 19. Grid voltages and currents when the step reference from 0 to $10 \mathrm{~kW}$ has been applied.

A different value of purely active power reference has been injected to the grid and the experimental results are shown in Figure 20. 


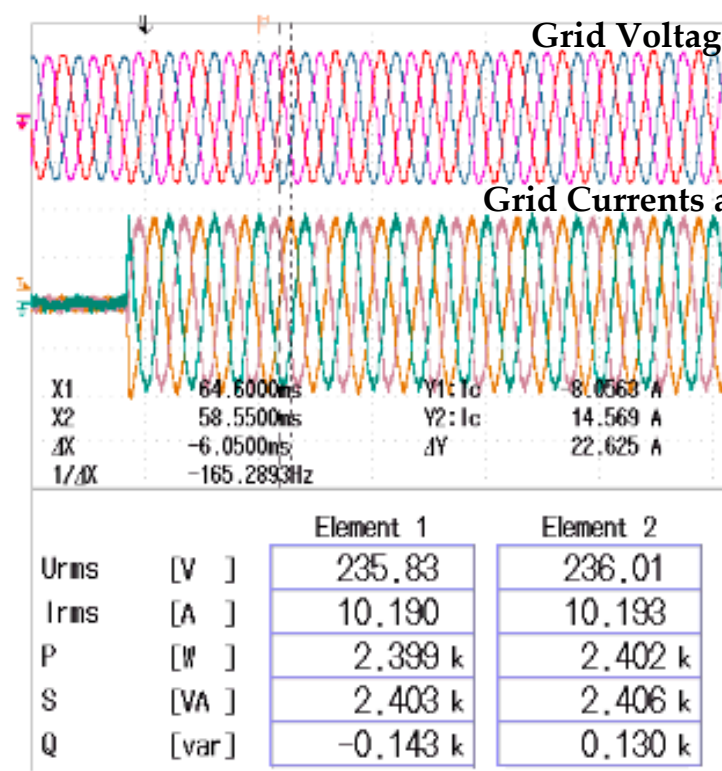

(a)

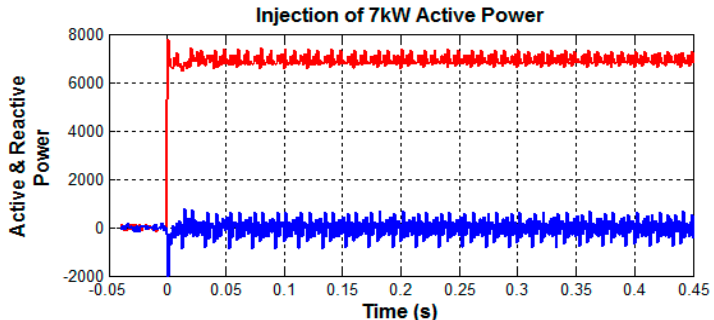

Active Power
Reactive Power

(b)

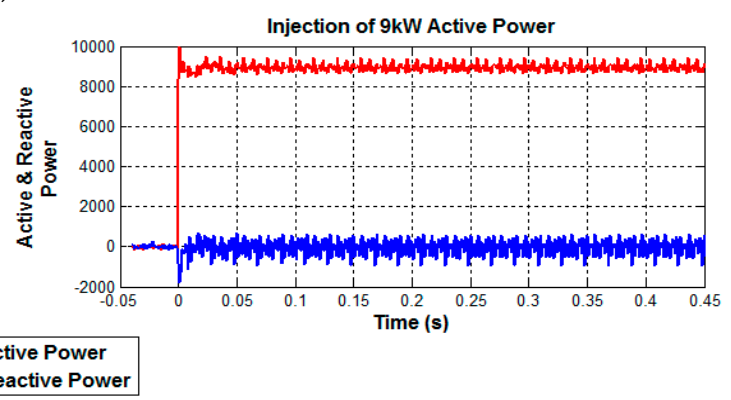

(c)

Figure 20. Injection of purely active power: (a) Results captured from oscilloscope with power reference step is set from 0 to $7.5 \mathrm{~kW}(0.75 \mathrm{p} . \mathrm{u})$; (b) Results captured from the control desk when power reference is set to $7 \mathrm{~kW}$ (0.7 p.u); (c) Results captured from the control desk when power reference is set to $9 \mathrm{~kW}$ (0.9 p.u).

Figure 20a shows the captured result from the oscilloscope based on purely active power injection. The active power reference has been boosted up from zero to $7.5 \mathrm{~kW}$ in Figure 20a. In Figure 20b,c, the results are captured from the control desk. The active power reference step has been applied from zero to $7 \mathrm{~kW}$ in Figure 20b,c, $9 \mathrm{~kW}$ active power reference has been set, respectively. The system is working fine and the system has reached its steady state condition at $t=0.02 \mathrm{~s}$. In this test, the reactive power measurement in the three cases shown in Figure 20 are equal to zero, which matches with the value of reactive power reference that has been set in the experiments.

\subsection{Control of Reactive Power Delivery}

In these case studies, the reactive power reference step has been applied in order to see the behaviour of the system at both transients and steady state condition. As it can be concluded from the plots, a very smooth transient state condition of the reactive power injection can be seen in Figure 20. The result captured from the oscilloscope is shown in Figure 21 when purely reactive power has been injected. The reactive power reference has been set to $6 \mathrm{kVar}(0.6 \mathrm{p} . \mathrm{u})$. 


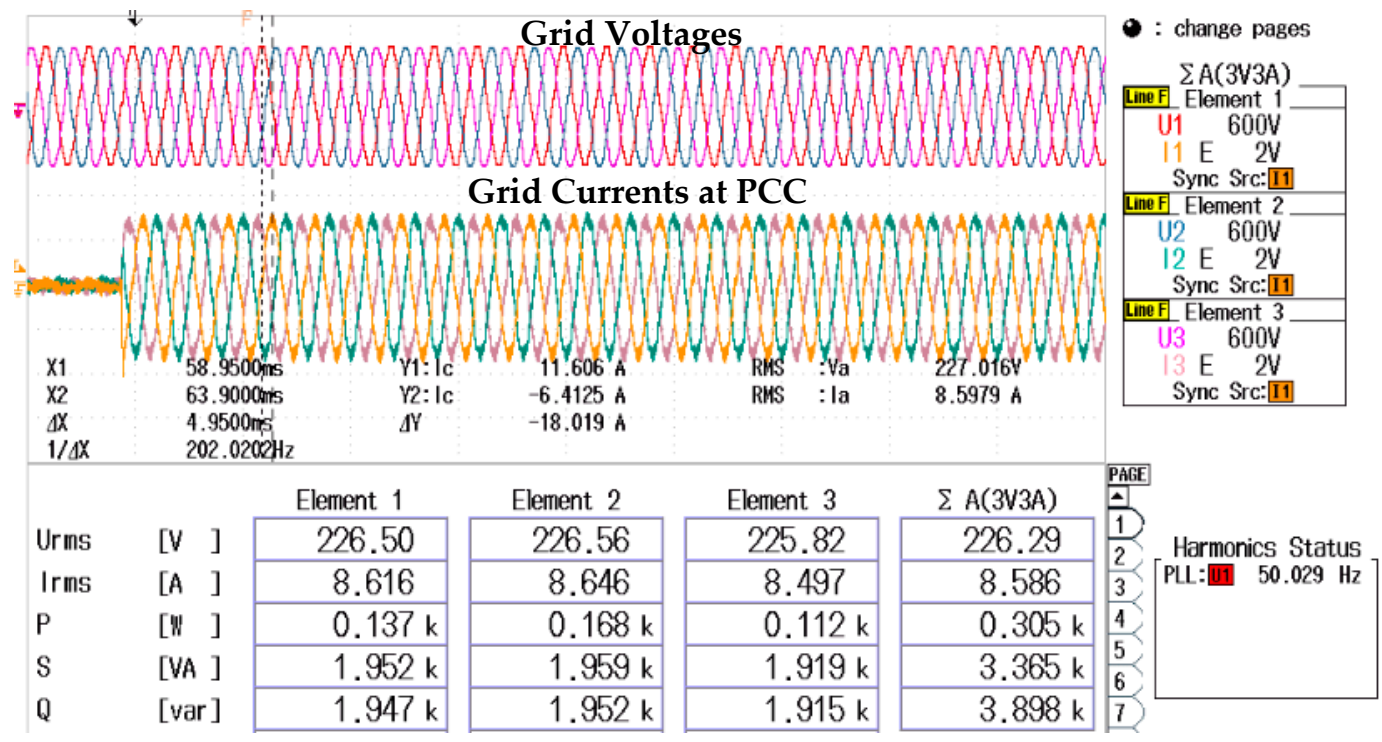

Figure 21. Injection of purely reactive power.

Based on the results obtained, the system is capable to control the reactive power. It is understandable that there are power losses occurred during the experimental, less than $0.2 \mathrm{kvar}$, thus the result shown in Figure 21 is satisfactory. Figure 22 is the zoom version of the waveforms shown in Figure 21.

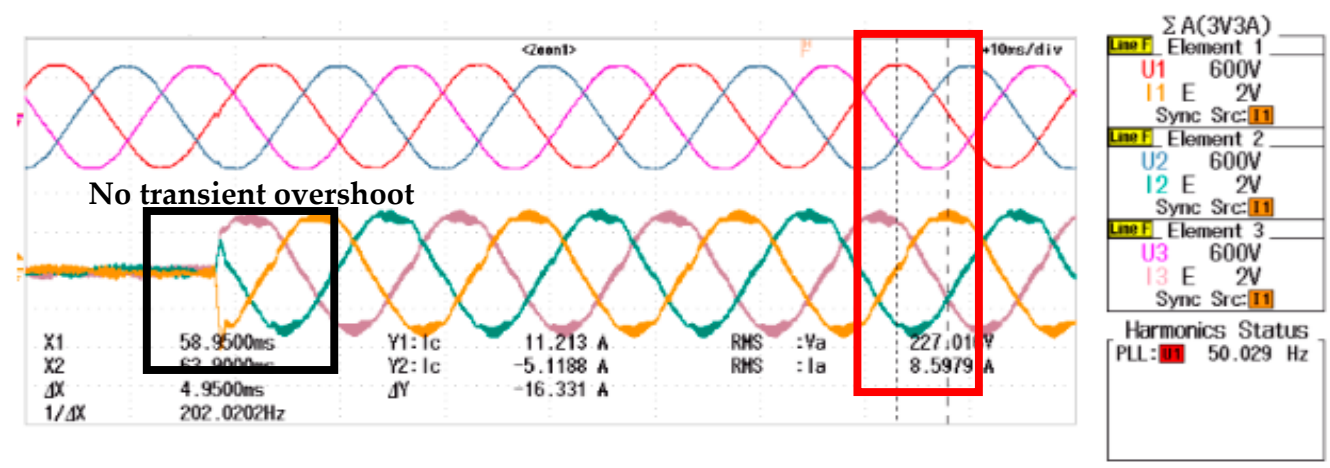

Figure 22. Injection of reactive power when step change has been applied from 0 to $6 \mathrm{kVar}(0.6 \mathrm{p} . \mathrm{u})$.

By referring to the red box in Figure 22, it can be seen that the current, I1 lags the voltage, U1 by almost $90^{\circ}$ when purely reactive power is injected. Considering that the system is working at $50 \mathrm{~Hz}$ fundamental frequency, the time for one full cycle is equal to $20 \mathrm{~ms}$.

Since one full cycle is equivalent to $360^{\circ}, \Delta X=4.95 \mathrm{~ms}$ is considered as $89.1^{\circ}$ phase lag $\left[\left(360^{\circ} \times 4.95 \mathrm{~ms}\right) / 20 \mathrm{~ms}\right]$. In Figure 23 , the experimental results captured from the control desk considering different values of active and reactive power injections to the grid have been presented. 


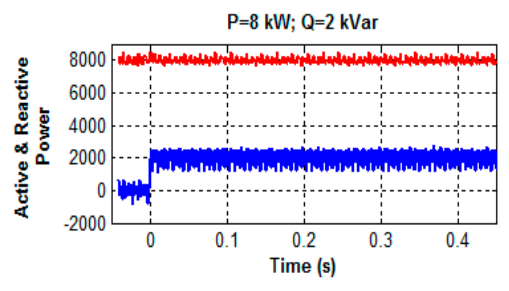

(a)

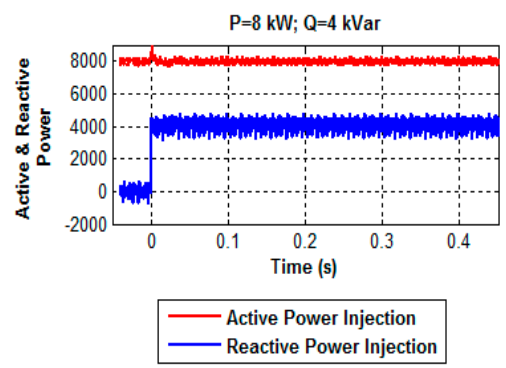

(b)

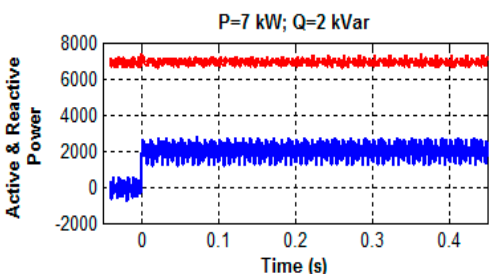

(c)

Figure 23. Injection of reactive power: (a) Step change from 0 to $2 \mathrm{kVar}$ when active power injection is $8 \mathrm{~kW}$; (b) Step change from 0 to $4 \mathrm{kVar}$ when active power injection maintain at $8 \mathrm{~kW}$; (c) Step change from 0 to $2 \mathrm{kVar}$ when active power injection is $7 \mathrm{~kW}$.

The reactive power reference step has been applied in order to see the behavior of the system at both transients and steady state condition. As it can be concluded from the plots, a very smooth transient state condition of the reactive power injection can be seen in Figure 23 for all the three case studies. Based on the experimental results shown from Figure 16 until Figure 23, it can be concluded that the proposed system based on the VF-based synchronization is able to control the injection of active and reactive power to the grid. In general, the presented results at both simulation and experimental endorse the accuracy of VF estimation, since the synchronization with the grid and the corresponding control of the active and reactive power injection to the PCC is based on the VF signals.

\section{Conclusions}

This work presented a control method based on VF synchronization that permits one to control the active/reactive power delivery in a remote point of the grid, as for instance at the transformer connection point. The results from the simulation as well as the experimental studies prove that the VF based synchronization is a good method to estimate the grid voltage condition without using any voltage sensor. Furthermore the proposed VF-based synchronization have shown to have a good behaviour which contribute to achieve a good performance of overall systems in the experimental validation.

The fast synchronization and the smooth reference tracking achieved in transient conditions, have demonstrated the effectiveness of the DSOGI-VF and the PR current controller used in the proposed system. The most obvious finding that emerges from this study is that the VF estimation is reliable to estimate the voltage at different points along the grid as long as the parameters needed for the estimation are available. Therefore, it is possible to control the power injection/absorption remotely. Additionally, the presented control solution in this paper offers a flexible way to control the active and reactive power. The possibility of controlling the active and reactive power flow at remote location in the grid can be useful for several applications, especially in the microgrid system.

Acknowledgments: This work has been partially supported by the Ministry of Economy and Competitiveness under the projects ENE2016-79493-R. Any opinions, findings and conclusions or recommendations expressed in this material are those of the authors and do not necessarily reflect those of the host institutions and funders.

Author Contributions: Pedro Rodriguez provided the supervision and revised the paper. Alvaro Luna proposed the control strategy, conducted the analysis and revised the paper. Joan Rocabert validated the control strategy in experiment. Nurul Fazlin Roslan conducted the analysis, validated the control strategy in simulation and experiment, and also conducted the writing of the paper. Jose Ignacio Candela contributed in the analysis.

Conflicts of Interest: The authors declare no conflict of interest. 


\section{Abbreviations}

The following abbreviations are used in this manuscript:

$\begin{array}{ll}\text { RES } & \text { Renewable Energy Source } \\ \text { PCC } & \text { Point of Common Connection } \\ \text { TSO } & \text { Transmission System Operators } \\ \text { VSC } & \text { Voltage Source Converters } \\ \text { VF } & \text { Virtual Flux } \\ \text { LCL } & \text { Inductor (L), Capacitor (C), Inductor (L) } \\ \text { DPC } & \text { Direct Power Control } \\ \text { VOC } & \text { Voltage Oriented Control } \\ \text { DSOGI-FLL } & \text { Dual Second Order Generalized Integrator with Frequency Locked Loop } \\ \text { DSOGI-QSG } & \text { Dual Second Order Generalized Integrator with Quadrature Signal Generator } \\ \text { FLL } & \text { Frequency Locked Loop } \\ \text { PNSC } & \text { Positive and Negative Sequence Components extractor } \\ \text { DSOGI-VF } & \text { Dual Second Order Generalized Integrator based Virtual Flux } \\ \text { PI } & \text { Proportional Integral } \\ \text { PR } & \text { Proportional Resonant } \\ \text { GI } & \text { Generalized Integrator } \\ \text { PWM } & \text { Pulse Width Modulation } \\ \text { SVM } & \text { Space Vector Modulation } \\ \text { PNS } & \text { Positive and Negative Sequence }\end{array}$

\section{References}

1. IRENA. REthinking Energy 2017: Accelerating Global Energy Transformation; International Renewable Energy Agency (IRENA): Abu Dhabi, UAE, 2017; Available online: http:/ / www.irena.org/DocumentDownloads / Publications/IRENA_REthinking_Energy_2017.pdf (accessed on 1 December 2017).

2. Teodorescu, R.; Liserre, M.; Rodriguez, P. Grid Converters for Photovoltaic and Wind Power Systems; John Wiley \& Son: Hoboken, NJ, USA, 2011.

3. Rodriguez, P.; Luna, A.; Munoz Aguilar, R.S.; Teodorescu, R.; Blaabjerg, F.; Otadui, I.E. A stationary reference frame grid synchronization converters under adverse grid conditions. IEEE Trans. Power Electron. 2012, 27, 99-112. [CrossRef]

4. Hassaine, L.; Olias, E.; Quintero, J.; Salas, V. Overview of power inverter topologies and control structures for grid connected photovoltaic systems. Renew. Sustain. Energy Rev. 2014, 30, 796-807. [CrossRef]

5. Luna, A.; Rocabert, J.; Ignacio Candela, J.; Hermoso, J.R.; Teodorescu, R.; Blaabjerg, F.; Rodriquez, P. Grid voltage synchronization for distributed generation systems under grid fault conditions. IEEE Trans. Ind. Appl. 2015, 51, 3414-3425. [CrossRef]

6. Hansen, S.; Malinowski, M.; Blaabjerg, F.; Kazmierkowski, M.P. Sensor-less control strategies for PWM rectifier. In Proceedings of the 15th Annual IEEE Applied Power Electronics Conference and Exposition, New Orleans, Louisiana, 6-10 February 2000; pp. 832-838.

7. Malinowski, M.; Kazmierkowski, M.P.; Hansen, S.; Blaabjerg, F.; Marques, G.D. Virtual-flux-based direct power control of three-phase PWM rectifiers. IEEE Trans. Ind. Appl. 2001, 37, 1019-1027. [CrossRef]

8. Malinowski, M.; Kazmierkowski, M.P.; Trzynadlowski, A.M. A comparative study of control techniques for PWM rectifiers in AC adjustable speed drives. IEEE Trans. Power Electron. 2003, 18, 1390-1396. [CrossRef]

9. Norniella, J.G.; Cano, J.M.; Orcajo, G.A.; Rojas, C.H.; Pedrayes, J.F.; Cabanas, M.F.; Melero, M.G. Improving the dynamics of virtual-flux-based control of three-phase active rectifiers. IEEE Trans. Ind. Electron. 2014, 61, 177-187. [CrossRef]

10. Razali, A.M.; George, G. An Analysis of Direct Power Control for Three Phase AC-DC Converter; IEEE Industry Applications Society Annual Meeting (IAS): Las Vegas, NV, USA, 2012; pp. 1-7.

11. Razali, A.; Rahman, A.; George, G.; Rahim, N. Analysis and design of new switching look-up table for virtual flux direct power control of grid connected three phase PWM AC-DC converter. IEEE Trans. Ind. Appl. 2015, 51, 1189-1200. [CrossRef] 
12. Antoniewicz, P.; Kazmierkowski, M.P. Virtual-flux-based predictive direct power control of AC/DC converters with online inductance estimation. IEEE Trans. Ind. Electron. 2008, 55, 4381-4390. [CrossRef]

13. Tao, Y.; Wu, Q.; Tang, W.; Wang, L. Voltage sensorless predictive direct power control of three-phase PWM converters. IET Power Electron. 2016, 9, 1009-1018. [CrossRef]

14. Bian, C.; Shi, C.; Song, C.; Wang, A. Study of the control system of three-level PWM rectifier based on virtual flux oriented. In Proceedings of the International Conference. Intelligent Human-Machine Systems and Cybernetics, College of Computer Science \& Technology of Zhejiang University, Hangzhou, China, 26-27 August 2011; pp. 53-56.

15. Kulka, A. Sensor-Less Digital Control of Grid Connected Three Phase Converters For Renewable Sources. Ph.D. Thesis, Norwegian University of Science and Technology, Trondheim, Norway, 2009.

16. Suul, J.A. Control of Grid Integrated Voltage Source Converters under Unbalanced Conditions-Development of an Online Frequency Adaptive Virtual Flux Based Approach. Ph.D. Thesis, Norwegian University of Science and Technology, Trondheim, Norway, 2012.

17. Suul, J.A.; Luna, A.; Rodríguez, P.; Undeland, T. Voltage-sensor-less synchronization to unbalanced grids by frequency-adaptive virtual flux estimation. IEEE Trans. Ind. Electron. 2012, 59, 2910-2923. [CrossRef]

18. Suul, J.A.; Luna, A.; Rodriguez, P.; Undeland, T. Frequency-adaptive virtual flux estimation for grid synchronization under unbalanced conditions. In Proceedings of the Industrial Electronics Conference, Glendale, AZ, USA, 7-10 November 2010; pp. 486-492.

19. Zhang, J.; Wang, H.; Zhu, M.; Cai, X. Control implementation of the full-scale wind power converter without grid voltage sensors. In Proceedings of the 2014 International Power Electronics Conference, Hiroshima, Japan, 18-21 May 2014; pp. 1753-1760.

20. Wrona, G.; Malon, K. Sensorless operation of an active front end converter with LCL filter. In Proceedings of the 2014 IEEE 23rd International Symposium on Industrial Electronics, ISIE 2014, Istanbul, Turkey, 1-4 June 2014; pp. 2697-2702.

21. Gullvik, W.; Norum, L.; Nilsen, R. Active damping of resonance oscillations in LCL-filters based on virtual flux and virtual resistor. In Proceedings of the 12th European Conference on Power Electronics and Applications, Aalborg, Denmark, 2-5 September 2007; pp. 1-10.

22. Roslan, N.F.; Suul, J.A.; Luna, A.; Candela, J.I.; Rodriguez, P. A simulation study of proportional resonant controller based on the implementation of frequency adaptive virtual flux estimation with the LCL ilter. In Proceedings of the IEEE Industrial Electronics Society, Yokohama, Japan, 9-12 November 2015; pp. 1934-1941.

23. Peña-Alzola, R.; Liserre, M.; Blaabjerg, F.; Sebastían, R.; Dannehl, J.; Fuchs, F.W. Analysis of the passive damping losses in LCL-filter-based grid converters. IEEE Trans. Power Electron. 2013, 28, 2642-2646. [CrossRef]

24. Zammit, D.; Staines, C.S.; Apap, M. Comparison between PI and PR current controllers in grid connected PV inverters. Int. J. Electr. Comput. Electron. Commun. Eng. 2014, 8, 224-229. 